\title{
THE CARDIOGRAM OF CONGENITAL AND ACQUIRED RIGHT VENTRICULAR HYPERTROPHY
}

\author{
BY \\ J. F. GOODWIN AND Z. H. ABDIN \\ From the Department of Medicine, Postgraduate Medical School of London
}

Received November 20, 1958

In recent years the accuracy of cardiographic diagnosis of ventricular hypertrophy has greatly improved, largely as a result of the introduction of multiple chest leads and unipolar leads. The diagnosis of left ventricular hypertrophy has presented considerably less difficulty than that of right hypertrophy probably because the left ventricle is normally dominant over the right. But even with the use of multiple unipolar and bipolar leads, right ventricular hypertrophy of appreciable degree not infrequently fails to give any cardiographic evidence of its presence. The criteria for right ventricular (R.V.) hypertrophy proposed by Wilson et al. (1944), Goldberger (1947), Myers et al. (1948), Sokolow and Lyon (1949), and Myers (1950) are now generally accepted. They consist of a dominant $\mathrm{R}$ wave in right præcordial leads (V1), with a delayed intrinsicoid deflection and often with $\mathrm{T}$ wave inversion. The $\mathrm{R}$ wave may be preceded by a small q wave (Fowler et al., 1952). Complete or partial bundle-branch block patterns may also occur. So-called extreme clockwise rotation indicated by a dominant $S$ wave in V5, and in many cases a dominant $R$ in VR, completes the picture of severe R.V. hypertrophy. In less severe cases many, or all of these signs are absent, but the use of lead V4R has resulted in the detection of cases that would otherwise have been missed (Myers et al., 1948; and Roseöman, 1950) We have studied the value of lead V4R in R.V. hypertrophy in 252 adult subjects (Camerini et al., 1956), and found that an Rs pattern in V4R was the sole evidence of R.V. hypertrophy in an appreciable number of cases, and we considered V4R to be a valuable addition to the cardiographic detection of R.V. hypertrophy.

Even with the addition of V4R, right ventricular hypertrophy often escapes cardiographic detection, particularly when the hypertrophy is acquired rather than congenital. Thus patients with mitral stenosis or cor pulmonale (the two commonest causes of acquired R.V. hypertrophy) may show little or no cardiographic evidence, in sharp contrast to patients with congenital hypertrophy due to pulmonary stenosis or hypertension.

The cardiographic changes in mitral stenosis and congenital heart disease have been compared and contrasted by Cosby et al. (1952 and 1953) who correlated the cardiographic evidence of R.V. hypertrophy with R.V. pressure, flow, and work, and noted that in præcordial leads gross differences were present between mitral disease and congenital heart disease. Abnormal cardiograms appeared at lower levels of right ventricular work in congenital heart disease than in mitral disease, and the cardiogram was more helpful in predicting R.V. hypertrophy in the former than in the latter group. They did not include cases with other forms of acquired R.V. hypertrophy, nor did they have autopsy controls. Walker et al. (1955) compared the cardiographic findings with the thickness of the right ventricle in 22 cases of R.V. hypertrophy, where the full diagnosis was not given, and found that only 5 fulfilled at least one of the criteria of Sokolow and Lyon (1949) for R.V. hypertrophy, but that the cardiographic degree of R.V. hypertrophy increased with the thickness of the right ventricle. In a subsequent paper (Scott et al., 1955) the same workers found anatomical R.V. hypertrophy in 8 of 12 cases with cardiographic right ventricular hypertrophy: 11 of these had diseases likely to cause 
an increased pulmonary vascular resistance and R.V. hypertension, but measurements were not made. Walker et al. considered that the mass of the right ventricle, pulmonary hypertension, increased pulmonary vascular resistance, and possibly cardiac rotation, all contributed to the cardiographic picture of R.V. hypertrophy.

Scott et al. (1955) studied 32 patients with mitral disease, and compared the cardiographic patterns with pulmonary artery pressure, pulmonary resistance, and mitral valve area. They claimed that if the total pulmonary resistance was 1000 dynes $/ \mathrm{sec} . / \mathrm{cm} . .^{-5}$ or more, the cardiogram usually showed either incomplete right bundle-branch block or R.V. hypertrophy. If the left ventricle was enlarged by mitral regurgitation or aortic disease the total pulmonary resistance might exceed this figure without signs of cardiographic R.V. hypertrophy developing. Trounce (1952) found a poor relationship between the signs of R.V. hypertrophy in præcordial leads and the mean pulmonary artery pressure in 35 cases of mitral stenosis. By contrast, Whitaker (1954) found a positive relationship between the patterns in $\mathrm{V} 1$, and the height of the pulmonary artery pressure, a dominant $R$ wave occurring in 9 of 12 patients with mean pressures over $50 \mathrm{~mm}$. $\mathrm{Hg}$.

Davies et al. (1953) and Goodwin et al. (1955), using a simple cardiographic grading of severity of R.V. hypertrophy in mitral disease, found that appreciable or severe cardiographic R.V. hypertrophy only occurred with considerable or gross pulmonary hypertension, and that with moderate pulmonary hypertension the cardiogram was often virtually normal, even though tight mitral stenosis was present. Thomas (1951) has shown that the cardiogram in pneumoconiosis, in which R.V. hypertrophy commonly occurs, may often be normal, and Mounsey et al. (1952) have shown that the $\mathbf{R}$ wave in V4R may increase during an exacerbation of heart failure in cor pulmonale, and then return to normal on recovery, as we have shown in mitral stenosis (Camerini et al., 1956).

As has already been mentioned, the cardiographic evidence of R.V. hypertrophy in congenital heart disease is usually much more striking, probably, as Cosby et al. (1953) have pointed out, because R.V. pressures are usually considerably higher in congenital heart disease than in mitral and other acquired disease.

In 1952 Campbell compared the findings in a personal series of congenital heart disease patients (Goodwin, 1952) with those of Woods (1952) in the tetralogy of Fallot, and of Trounce (1952) in mitral stenosis. He noted that the R wave in V1 was small in the normal and in mitral stenosis, being less than $10 \mathrm{~mm}$. in 90 per cent, but in the tetralogy was $10 \mathrm{~mm}$. or more in 80 per cent of cases.

The present work was undertaken with a view to clarifying the cardiographic differences between congenital and acquired R.V. hypertrophy, to determine the reasons for the differences, and to produce a cardiographic grading of degrees of severity of R.V. hypertrophy that would aid in assessment of the severity of the disease, and facilitate diagnosis and prognosis. The study includes several forms of acquired as well as of congenital right ventricular hypertrophy, and both pathological and hæmodynamic studies of right ventricular function and pathology have been made.

\section{MATERIAL AND Methods}

A total of 117 cases have been studied, 45 having R.V. hypertrophy due to congenital heart disease, and 72 hypertrophy due to acquired disease. The number of cases with each diagnosis are shown below, and the figures in brackets indicate the 39 cases with necropsy control.

\section{Acquired Group}

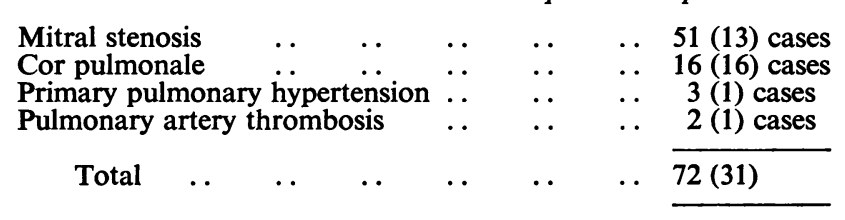




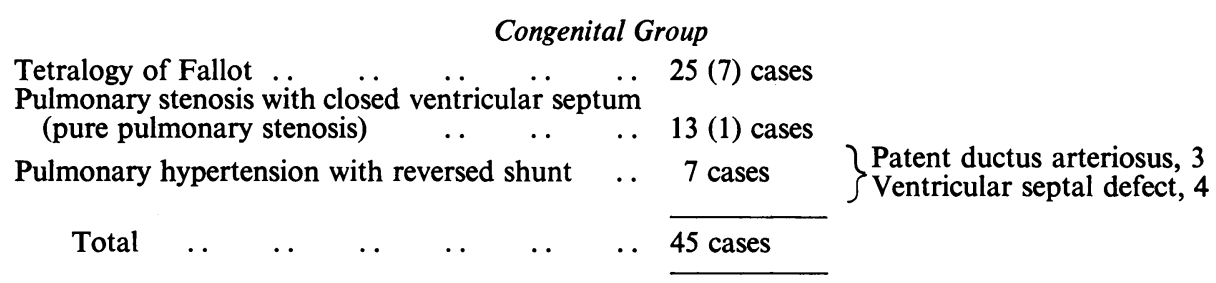

Patients with cardiographic evidence of left ventricular enlargement and those with right bundlebranch block were excluded. Patients with atrial septal defects were also excluded from the congenital group, because of the tendency to right bundle-branch block, which confuses the cardiographic picture. Patients under the age of 7 were not admitted because of the physiological cardiographic right ventricular dominance in small children.

Pulmonary artery pressures and flows were measured by cardiac catheterization in all groups except the tetralogy of Fallot and cor pulmonale.

Cardiac catheterization data were available on all the autopsied cases except those with Fallot's tetralogy and cor pulmonale and 4 cases of mitral stenosis: these last 4 have, therefore, not been included in the general comparison between hæmodynamic and cardiographic abnormalities.

Measurements of right and left ventricular thickness were available in 28 cases only: 4 tetralogy of Fallot, 7 mitral stenosis, 16 cor pulmonale, and 1 primary pulmonary hypertension.

Cardiographic Criteria. All patients had 12 lead cardiograms, and most had lead V4R. The ventricular complex and T waves were examined in the præcordial unipolar leads V4R, V1, V3 and V5, and in lead VR. The shape and height of the $\mathbf{P}$ waves were noted. The cardiograms were recorded with a Sanborn Visocardiette, Cambridge direct writing machine, and Elmqvist and Victor photographic instruments. Conventional standardization of $1 \mathrm{~cm} .=1 \mathrm{mv}$. was employed.

Pathological Criteria. In many cases no exact measurements of right and left ventricular thickness were given, but where these were available, a thickness of $5 \mathrm{~mm}$. or more at the right ventricular out-flow tract was considered evidence of R.V. hypertrophy according to our previous criteria (Pagnoni and Goodwin, 1952; Camerini et al., 1956; and Goodwin, 1958.) A thickness of the left ventricle of more than $15 \mathrm{~mm}$. was considered evidence of hypertrophy. The ratio of right to left ventricular thickness ( $\mathrm{RV} / \mathrm{LV}$ ratio) was obtained in all these cases.

\section{RESULTS}

(1) The Ventricular Complex in leads V4R, V5, and VR.

The distribution of the different patterns in the groups is shown in Tables, I, II, and III. A predominantly positive deflection in V4R, indicative of R.V. hypertrophy (Camerini et al., 1956), occurred more frequently in the congenital than in the acquired series. Over half the patients with cor pulmonale or with mitral stenosis had no evidence of R.V. hypertrophy in this lead, which we consider to be probably the most sensitive index of R.V. hypertrophy (Camerini et al., 1956). All the 3 cases of primary pulmonary hypertension had a predominantly positive deflection, and thus resembled the congenital cases, only 2 of which had a mainly negative deflection. A qR pattern, which probably represents considerable R.V. hypertrophy, was present in only 5 of 51 cases of mitral disease, in contrast to 7 of 25 cases of the tetralogy.

In V5 the reverse was the case, the majority of acquired cases having a predominantly positive, and the congenital cases a predominantly negative, deflection. But the contrast between the groups was more striking with regard to mitral stenosis, only 7 of 51 cases having the negative or rS deflection, in contrast to 16 of 24 cases of Fallot's tetralogy and 6 of 7 cases of congenital pulmonary hypertension. There were interesting differences within the main groups. The cases with cor pulmonale resembled the tetralogy in having the rS pattern in 12 of 16 cases, while the cases with pure pulmonary stenosis resembled the mitral cases in having it in only 4 of 13 cases. A qR pattern occurred in only 9 patients, all with mitral stenosis. 
TABLE I

Ventricular Complex in Lead V4R

\begin{tabular}{|c|c|c|c|c|c|c|c|c|c|c|c|c|}
\hline \multirow[b]{2}{*}{ Diagnosis } & \multicolumn{5}{|c|}{$\begin{array}{c}\text { Predominant } \\
\text { positive deflection }\end{array}$} & \multicolumn{6}{|c|}{$\begin{array}{l}\text { Predominant negative or } \\
\text { biphasic deflection }\end{array}$} & \multirow[b]{2}{*}{$\begin{array}{l}\text { Total } \\
\text { cases }\end{array}$} \\
\hline & Rs & $\mathbf{R}$ & $\mathrm{qR}$ & rSR & Total & rS & $\mathrm{qS}$ & Qr & RS & QR & Total & \\
\hline Mitral stenosis .. & 8 & 9 & 5 & 1 & 23 & 15 & 4 & 1 & 8 & 0 & 28 & 51 \\
\hline Cor pulmonale .. & $2^{*}$ & 2 & 0 & 3 & 7 & 2 & 3 & $2 \dagger$ & 2 & 0 & 9 & 16 \\
\hline $\begin{array}{c}\text { Primary pulmonary hyper- } \\
\text { tension }\end{array}$ & 0 & 0 & 3 & 0 & 3 & 0 & 0 & 0 & 0 & $\mathbf{0}$ & 0 & 3 \\
\hline 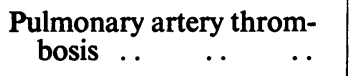 & 0 & 0 & 1 & 0 & 1 & 1 & 0 & 0 & $\mathbf{0}$ & $\mathbf{0}$ & 1 & 2 \\
\hline Tetralogy of Fallot & 2 & 10 & 7 & 4 & 23 & 1 & 0 & 0 & 0 & 1 & 2 & 25 \\
\hline Pure pulmonary stenosis & 0 & 8 & 3 & 2 & 13 & 0 & 0 & 0 & 0 & 0 & 0 & 13 \\
\hline $\begin{array}{c}\text { Congenital pulmonary } \\
\text { hypertension .. .. }\end{array}$ & 1 & 3 & 3 & 0 & 7 & 0 & 0 & 0 & 0 & 0 & 0 & 7 \\
\hline
\end{tabular}

Figures denote number of cases.

* One with qRs. † One with QrS.

TABLE II

Ventricular CompleX in Lead V5

\begin{tabular}{|c|c|c|c|c|c|c|c|c|c|c|c|c|}
\hline \multirow{2}{*}{ Diagnosis } & \multicolumn{5}{|c|}{$\begin{array}{c}\text { Predominant positive } \\
\text { deflection }\end{array}$} & \multicolumn{6}{|c|}{$\begin{array}{l}\text { Predominant negative or } \\
\text { biphasic deflection }\end{array}$} & \multirow{2}{*}{$\begin{array}{l}\text { Total } \\
\text { cases }\end{array}$} \\
\hline & Rs & $\mathbf{R}$ & $\mathrm{qR}$ & rSR & Total & $\mathrm{rS}$ & $\mathrm{qS}$ & Qv & RS & QR & Total & \\
\hline Mitral stenosis .. & qRS:2 & 7 & 9 & 0 & 44 & 5 & $\mathbf{0}$ & 0 & 2 & 0 & $i$ & 51 \\
\hline Cor pulmonale .. & 2 & 2 & $\mathbf{0}$ & 0 & 4 & 9 & $\mathbf{0}$ & $\mathbf{0}$ & 3 & 0 & 12 & 16 \\
\hline $\begin{array}{l}\text { Primary pulmonary hyper- } \\
\text { tension }\end{array}$ & 2 & 0 & $\mathbf{0}$ & $\mathbf{0}$ & 2 & 1 & $\mathbf{0}$ & $\mathbf{0}$ & 0 & 0 & 1 & 3 \\
\hline $\begin{array}{l}\text { Pulmonary artery throm- } \\
\text { bosis .. }\end{array}$ & $\underset{0}{\mathrm{qRS}: 2}$ & 0 & $\mathbf{0}$ & $\mathbf{0}$ & 2 & $\mathbf{0}$ & 0 & $\mathbf{0}$ & $\mathbf{0}$ & $\mathbf{0}$ & $\mathbf{0}$ & 2 \\
\hline Tetralogy of Fallot & $6^{*}$ & 2 & $\mathbf{0}$ & $\mathbf{0}$ & 8 & 10 & 1 & $\mathbf{0}$ & 5 & $\mathbf{0}$ & 16 & $24^{*} \dagger$ \\
\hline Pure pulmonary stenosis & qRS:2 & 0 & $\mathbf{0}$ & $\mathbf{0}$ & 9 & 4 & 0 & $\mathbf{0}$ & $\mathbf{0}$ & $\mathbf{0}$ & 4 & 13 \\
\hline $\begin{array}{c}\text { Congenital pulmonary } \\
\text { hypertension ... }\end{array}$. & 1 & 0 & 0 & 0 & 1 & 5 & 0 & 0 & 1 & 0 & 6 & 7 \\
\hline
\end{tabular}

Figures denote number of cases.

* $\mathrm{q}$ before $\mathrm{R}$ or $\mathrm{r}$ in one of each of these. † 55 was not recorded in one case. 
TABLE III

VeNTRICUlar COMPLEX IN LEAD VR

\begin{tabular}{|c|c|c|c|c|c|c|c|c|c|c|c|c|}
\hline \multirow{2}{*}{ Diagnosis } & \multicolumn{5}{|c|}{$\begin{array}{c}\text { Dominant positive } \\
\text { deflection }\end{array}$} & \multicolumn{6}{|c|}{$\begin{array}{l}\text { Dominant negative or } \\
\text { biphasic deflection }\end{array}$} & \multirow{2}{*}{ Total } \\
\hline & Rs & $\mathrm{R}$ & $\mathrm{qR}$ & $\mathrm{rS}$ & Total & $\mathrm{rS}$ & $\mathrm{qS}$ & Qr & RS & QR & Total & \\
\hline Mitral stenosis .. & 0 & 0 & 5 & 1 & 6 & 4 & 12 & 23 & 0 & 3 & 42 & $48^{*}$ \\
\hline Cor pulmonale .. & 0 & 1 & 5 & 2 & 8 & 2 & 1 & 1 & 0 & 4 & 8 & 16 \\
\hline $\begin{array}{l}\text { Primary pulmonary hyper- } \\
\text { tension }\end{array}$ & 0 & 0 & 0 & 0 & 0 & 0 & 0 & 2 & 0 & 1 & 3 & 3 \\
\hline $\begin{array}{c}\text { Pulmonary artery throm- } \\
\text { bosis } \ldots\end{array}$ & 0 & 0 & 0 & 0 & 0 & 0 & 0 & 1 & 0 & 1 & 2 & 2 \\
\hline Tetralogy of Fallot & 0 & 1 & 15 & 5 & 21 & 0 & 0 & 0 & 0 & 2 & 2 & $23 \dagger$ \\
\hline Pure pulmonary stenosis & 0 & 0 & 3 & 2 & 5 & 0 & 0 & 7 & 0 & 1 & 8 & 13 \\
\hline $\begin{array}{c}\text { Congenital pulmonary } \\
\text { hypertension .. }\end{array}$ & 0 & 0 & 4 & 1 & 5 & 0 & 1 & 1 & 0 & 0 & 2 & 7 \\
\hline
\end{tabular}

Figures denote number of cases.

* VR not recorded in 3 cases. $†$ VR not recorded in 2 cases.

In VR the patterns resembled those found in V4R, a mainly positive deflection being rare in mitral disease ( 6 of 48 cases), but common in the tetralogy (21 of 23 cases). Table IV shows the percentages of dominant positive and negative complexes in all groups in the three leads studied. When the individual groups are collected into two main groups, congenital and acquired, the difference in pattern is significant, as is shown in Table $\mathrm{V}$.

These patterns suggest a greater degree of right ventricular hypertrophy in congenital than in acquired cases, allowing for the differences and inconsistencies between the individual diagnostic groups within the two main groups. The possible reasons for this will be discussed later.

TABLE IV

Percentage of Cases with Dominant Negative or Positive Ventricular Complexes in Leads V4R, V5, aNd VR

\begin{tabular}{|c|c|c|c|c|c|c|c|c|c|c|c|c|}
\hline \multicolumn{6}{|c|}{ Diagnosis } & \multicolumn{3}{|c|}{$\begin{array}{c}\text { Dominant positive } \\
\text { deflection }\end{array}$} & \multicolumn{3}{|c|}{$\begin{array}{l}\text { Dominant negative or } \\
\text { biphasic deflection }\end{array}$} & \multirow{2}{*}{$\begin{array}{l}\text { Total } \\
\text { cases }\end{array}$} \\
\hline & & & & & & \multirow{2}{*}{$\begin{array}{l}\text { V4R } \\
45 \% \\
\end{array}$} & \multirow{2}{*}{$\begin{array}{c}\text { V5 } \\
86 \%\end{array}$} & \multirow{2}{*}{$\frac{\text { VR }}{13 \%}$} & \multirow{2}{*}{$\begin{array}{l}\mathrm{V} 4 \mathrm{R} \\
55 \% \\
\end{array}$} & \multirow{2}{*}{$\frac{\mathrm{V} 5}{14 \%}$} & \multirow{2}{*}{$-\frac{\mathrm{VR}}{87 \%}$} & \\
\hline Mitral stenosis & . & . & . & . & . & & & & & & & 51 \\
\hline Cor pulmonale & .. & . & . & . & .. & $44 \%$ & $25 \%$ & $50 \%$ & $56 \%$ & $75 \%$ & $50 \%$ & 16 \\
\hline \multicolumn{4}{|c|}{ Primary pulmonary hypertension } & . & .. & $100 \%$ & $67 \%$ & 0 & 0 & $33 \%$ & $100 \%$ & 3 \\
\hline \multicolumn{4}{|c|}{ Pulmonary artery thrombosis } & .. & .. & $50 \%$ & $100 \%$ & 0 & $50 \%$ & 0 & $100 \%$ & 2 \\
\hline \multicolumn{2}{|c|}{ Tetralogy of Fallot } & .. & .. & . & .. & $92 \%$ & $33 \%$ & $91 \%$ & $8 \%$ & $67 \%$ & $9 \%$ & 25 \\
\hline \multicolumn{3}{|c|}{ Pure pulmonary stenosis } & . & . & .. & $100 \%$ & $69 \%$ & $38 \%$ & 0 & $31 \%$ & $62 \%$ & 13 \\
\hline \multicolumn{4}{|c|}{ Congenital pulmonary hypertension } & .. & .. & $100 \%$ & $14 \%$ & $71 \%$ & 0 & $86 \%$ & $29 \%$ & 7 \\
\hline
\end{tabular}


TABLE V

Ventricular Complex in Combined AcQuired and Combined Congenital Groups in LEADS V4R, V5, AND VR

\begin{tabular}{|c|c|c|c|c|c|c|}
\hline & \multicolumn{2}{|c|}{ V4R } & \multicolumn{2}{|c|}{ V5 } & \multicolumn{2}{|c|}{ VR } \\
\hline & $\begin{array}{l}\text { Dominant } \\
\text { positive } \\
\text { deflection }\end{array}$ & $\begin{array}{l}\text { Biphasic or } \\
\text { dominant } \\
\text { negative } \\
\text { deflection }\end{array}$ & $\begin{array}{l}\text { Dominant } \\
\text { positive } \\
\text { deflection }\end{array}$ & $\begin{array}{l}\text { Biphasic or } \\
\text { dominant } \\
\text { negative } \\
\text { deflection }\end{array}$ & $\begin{array}{l}\text { Dominant } \\
\text { positive } \\
\text { deflection }\end{array}$ & $\begin{array}{l}\text { Biphasic or } \\
\text { dominant } \\
\text { negative } \\
\text { deflection }\end{array}$ \\
\hline \begin{tabular}{crrr} 
Combined & \multicolumn{2}{c}{ acquired } & right \\
ventricular & hypertrophy \\
group &. & $\ldots$ &..
\end{tabular} & 34 & 38 & 52 & 20 & 14 & $\begin{array}{l}\text { VR not } \\
\text { recorded in } \\
3 \text { cases } \\
55\end{array}$ \\
\hline \begin{tabular}{lrrr} 
Combined & \multicolumn{3}{c}{ congenital right } \\
ventricular & hypertrophy \\
group & $\ldots$ & $\ldots$ & $\ldots$
\end{tabular} & 43 & 2 & 18 & $\begin{array}{l}\text { V5 not } \\
\text { recorded in } \\
1 \text { case } \\
26\end{array}$ & 31 & $\begin{array}{l}\text { VR not } \\
\text { recorded in } \\
2 \text { cases } \\
12\end{array}$ \\
\hline $\begin{array}{llll}\chi^{2} \text { test } \ldots & \ldots & \ldots & \ldots\end{array}$ & $8 \cdot 5$ & & $14 \cdot 8$ & & $29 \cdot 2$ & \\
\hline
\end{tabular}

Figures denote number of cases.

(2) The Ratio of Positive to Negative Deflection in the Ventricular

Complex in leads VR4, V5, and VR.

The $\mathrm{R} / \mathrm{S}$ ratios in the three leads in all groups are shown in Table VI. In V4R the range was considerable, but the average in the acquired cases, with the exception of primary pulmonary hypertension, was roughly one-third of that in the congenital group. Primary pulmonary hypertension stood out in that the average of $8 \cdot 1$ approximated to that of the tetralogy $(6 \cdot 5)$, and to pure pulmonary stenosis $(10 \cdot 6)$, rather than to that of mitral stenosis $(2 \cdot 7)$, or to cor pulmonale $(1 \cdot 31)$.

TABLE VI

R/S RATIOS IN LEADS V4R, V5, AND VR

\begin{tabular}{|c|c|c|c|c|c|c|c|c|c|}
\hline & \multicolumn{3}{|c|}{ V4R } & \multicolumn{3}{|c|}{ V5 } & \multicolumn{3}{|c|}{ VR } \\
\hline & $\begin{array}{l}\text { Maxi- } \\
\text { mum }\end{array}$ & $\begin{array}{l}\text { Mini- } \\
\text { mum }\end{array}$ & Average & $\begin{array}{l}\text { Maxi- } \\
\text { mum }\end{array}$ & $\begin{array}{l}\text { Mini- } \\
\text { mum }\end{array}$ & Average & $\begin{array}{l}\text { Maxi- } \\
\text { mum }\end{array}$ & $\begin{array}{l}\text { Mini- } \\
\text { mum }\end{array}$ & Average \\
\hline Mitral stenosis $\quad \ldots$ & 20 & $0 \cdot 13$ & $2 \cdot 7$ & 25 & $0 \cdot 2$ & $7 \cdot 5$ & 5 & 0.04 & $0 \cdot 8$ \\
\hline Cor pulmonale $\quad \ldots \quad \quad \ldots$ & 3 & $0 \cdot 2$ & $1 \cdot 3$ & $6 \cdot 5$ & 0.6 & $1 \cdot 6$ & $2 \cdot 3$ & $0 \cdot 12$ & $1 \cdot 2$ \\
\hline $\begin{array}{c}\text { Primary pulmonary hyper- } \\
\text { tension } \ldots\end{array}$ & 16 & $1 \cdot 4$ & $8 \cdot 1$ & $2 \cdot 4$ & $0 \cdot 6$ & $1 \cdot 8$ & $2 \cdot 3$ & $0 \cdot 3$ & $1 \cdot 1$ \\
\hline Pulmonary artery thrombosis & 3 & $0 \cdot 3$ & $1 \cdot 7$ & 11 & $3 \cdot 3$ & $7 \cdot 2$ & 1 & 0.08 & $0 \cdot 5$ \\
\hline Average for all acquired cases & $10 \cdot 5$ & 0.5 & $3 \cdot 4$ & $11 \cdot 3$ & $1 \cdot 2$ & $4 \cdot 5$ & $2 \cdot 7$ & $0 \cdot 13$ & $0 \cdot 9$ \\
\hline Tetralogy of Fallot. . $\quad \ldots$ & 16 & 0.6 & $6 \cdot 5$ & $2 \cdot 7$ & $0 \cdot 2$ & $1 \cdot 2$ & 8 & 0.9 & 3 \\
\hline Pure pulmonary stenosis .. & 30 & 2 & $10 \cdot 6$ & 9 & $0 \cdot 5$ & $2 \cdot 8$ & 5 & $0 \cdot 3$ & $1 \cdot 4$ \\
\hline $\begin{array}{c}\text { Congenital pulmonary hyper- } \\
\text { tension }\end{array}$ & 22 & $4 \cdot 7$ & 13 & 2 & 0.2 & $0 \cdot 8$ & 5 & 0.8 & $2 \cdot 0$ \\
\hline \begin{tabular}{cccc} 
Average & for & all & \multicolumn{2}{c}{ congenital } \\
cases & $\ldots$ & $\ldots$ &.
\end{tabular} & $22 \cdot 7$ & $2 \cdot 4$ & 10 & $4 \cdot 6$ & 0.3 & $1 \cdot 6$ & 6 & 0.7 & $2 \cdot 1$ \\
\hline
\end{tabular}


The proportion of cases with a monophasic $\mathrm{R}$ wave was much greater in the congenital cases (approximately 50\%) than in the acquired cases (approximately $16 \%$ ).

In V5, the average $\mathrm{R} / \mathrm{S}$ ratio was much higher in the acquired cases $(4 \cdot 5)$, than in the congenital cases $(1 \cdot 6)$, but primary pulmonary hypertension and cor pulmonale resemble the congenital, rather than the acquired, pattern. In VR the average $\mathrm{R} / \mathrm{S}$ ratio in the acquired cases was half that in the congenital groups.

(3) The Voltage of the $R$ wave in $V 4 R$, of the $S$ wave in $V 5$, and of the $R$ wave in $V R$

These are shown in the different groups in Table VII. The maximum voltage of the $R$ wave in V4R and VR in any acquired case was 15 and $8 \mathrm{~mm}$. respectively, compared with 26 and $14 \mathrm{~mm}$.

TABLE VII

Voltage of R Waves in Leads V4R, and VR, and of S Waves in Lead V5

\begin{tabular}{|c|c|c|c|c|c|c|c|c|c|}
\hline & \multicolumn{3}{|c|}{ R V4R mm. } & \multicolumn{3}{|c|}{ S V5 mm. } & \multicolumn{3}{|c|}{ R VR mm. } \\
\hline & $\begin{array}{l}\text { Maxi- } \\
\text { mum }\end{array}$ & $\begin{array}{l}\text { Mini- } \\
\text { mum }\end{array}$ & Average & $\begin{array}{l}\text { Maxi- } \\
\text { mum }\end{array}$ & $\begin{array}{l}\text { Mini- } \\
\text { mum }\end{array}$ & Average & $\begin{array}{l}\text { Maxi- } \\
\text { mum }\end{array}$ & $\begin{array}{l}\text { Mini- } \\
\text { mum }\end{array}$ & Average \\
\hline Mitral stenosis & 15 & 0.5 & $3 \cdot 0$ & 20 & 0 & $4 \cdot 4$ & 6 & 0 & $1 \cdot 6$ \\
\hline Cor pulmonale & 6 & 0 & $2 \cdot 9$ & 17 & 0 & $7 \cdot 9$ & 6 & 0 & $3 \cdot 6$ \\
\hline $\begin{array}{c}\text { Primary pulmonary hyper- } \\
\text { tension } \ldots\end{array}$ & 14 & $3 \cdot 5$ & $8 \cdot 5$ & 8 & 6 & $7 \cdot 0$ & 8 & 2 & $6 \cdot 0$ \\
\hline Pulmonary artery thrombosis & 6 & 1 & $3 \cdot 5$ & 3 & 1 & $2 \cdot 0$ & 4 & $0 \cdot 5$ & $2 \cdot 3$ \\
\hline Average for all acquired cases & $10 \cdot 2$ & $1 \cdot 2$ & $3 \cdot 8$ & 12 & $1 \cdot 8$ & $5 \cdot 3$ & 6 & 0.6 & $3 \cdot 5$ \\
\hline Tetralogy of Fallot. . & 26 & 1 & $12 \cdot 8$ & 40 & 0 & $9 \cdot 7$ & 14 & 3 & $9 \cdot 1$ \\
\hline Pure pulmonary stenosis $\ldots$ & 24 & 2 & $9 \cdot 7$ & 16 & 2 & $6 \cdot 5$ & 10 & 1 & $6 \cdot 3$ \\
\hline 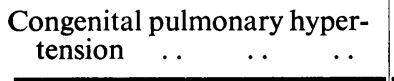 & 22 & 2 & $10 \cdot 3$ & 26 & 8 & $14 \cdot 7$ & 11 & 0 & $5 \cdot 3$ \\
\hline Average for all congenital cases & 24 & $1 \cdot 7$ & $10 \cdot 9$ & $27 \cdot 3$ & $3 \cdot 3$ & $10 \cdot 3$ & $11 \cdot 7$ & $1 \cdot 3$ & $7 \cdot 2$ \\
\hline
\end{tabular}

respectively in the congenital cases. In V5 the maximum voltage of the $\mathrm{S}$ wave was $20 \mathrm{~mm}$. in the acquired group (mitral stenosis), as compared with $40 \mathrm{~mm}$. in the congenital group. The voltage of $\mathrm{R}$ in V4R, $\mathrm{S}$ in V5, $\mathrm{R}$ in VR, in the cases of primary pulmonary hypertension resembled the congenital group rather than mitral stenosis. The voltage of $\mathrm{S}$ in V5 in cor pulmonale resembled congenital rather than mitral disease.

These measurements show a clear trend in the direction of greater R.V. hypertrophy in congenital than in acquired cases, but the range of values in the individual groups is so wide and the size of the groups so variable that further statistical analysis would not be likely to clarify the issue. Furthermore, the tendency for cor pulmonale (in V5) and primary pulmonary hypertension (in all leads) to resemble the pattern in the congenital rather than in the acquired groups makes comparison between the two main groups more difficult. But, in mitral stenosis, the largest acquired group, clearly the degree of R.V. hypertrophy tends to be less than in the congenital.

\section{(4) Praecordial $T$ waves}

In all groups the majority of $\mathrm{T}$ waves in leads V3 and V5 were positive, flat, or biphasic. Inversion occurred in V3 in 15 of 72 acquired cases and 8 of 37 congenital cases, and there was thus no significant difference between the groups $\left(\chi^{2}=0 \cdot 17\right)$. In V5 only 8 of 64 acquired, and 11 of 
34 congenital cases showed $\mathrm{T}$ wave inversion, but the difference was not highly significant $\left(\chi^{2}=\right.$ 3.62). In the congenital series $\mathrm{T}$ wave inversion in $\mathrm{V} 3$ and $\mathrm{V} 5$ was more frequent in lone pulmonary stenosis than in the tetralogy: it occurred in V3 in 3 of 13 cases of lone stenosis $(23 \%)$, as compared with 2 of 25 cases of the tetralogy $(8 \%)$, and in V 5 the T wave was inverted in 5 cases of the tetralogy $(20 \%)$, and 4 of lone stemosis $(30 \%)$. This difference presumably reflected the greater tendency for right ventricular embarrassment in lone pulmonary stenosis than in the tetralogy, for in the former, the right ventricular systolic pressure may exceed the left.

\section{(5) Cardiac Rhythm and $P$ waves}

Atrial fibrillation was present in 28 of the 51 patients with mitral disease, in only 2 of the 16 with cor pulmonale, and in none of the other acquired or the congenital cases. $P$ waves of $2.5 \mathrm{~mm}$. or more in height, suggesting right atrial enlargement, occurred in nearly half the cases of Fallot's tetralogy, but much less often in all the other groups, being present in only 3 of the cases of pure pulmonary stenosis. Broad and bifid $\mathbf{P}$ waves suggesting left atrial hypertrophy were found only in mitral cases (13 of 23) in sinus rhythm, and went with right atrial enlargement in 7 of these, 4 with gross and 3 with moderate pulmonary hypertension. A long P-R interval over $0.2 \mathrm{sec}$. was present in 4 of the acquired cases ( 2 with mitral disease, 1 with cor pulmonale, and 1 with primary pulmonary hypertension) and in 5 of 25 cases of the tetralogy of Fallot (Table VIII).

TABLE VIII

RhythM, P-R INTERVAL, AND P WAVes in all Groups

\begin{tabular}{|c|c|c|c|c|c|c|c|c|c|}
\hline \multicolumn{4}{|c|}{ Diagnosis } & \multirow{2}{*}{$\begin{array}{r}\text { RA+ } \\
\mathrm{LA}+ \\
7^{*}\end{array}$} & \multirow{2}{*}{$\frac{\mathrm{LA}+}{6}$} & \multirow{2}{*}{$\frac{\mathrm{RA}+}{2}$} & \multirow{2}{*}{$\begin{array}{c}\begin{array}{c}\text { Long P-R } \\
\text { interval }\end{array} \\
2 \dagger\end{array}$} & \multirow{2}{*}{$\frac{\begin{array}{c}\text { Atrial } \\
\text { fibrillation }\end{array}}{28}$} & \multirow{2}{*}{$\frac{\text { Normal }}{8}$} \\
\hline Mitral stenosis & .. & . & .. & & & & & & \\
\hline Cor pulmonale & .. & .. & .. & 0 & 0 & 1 & $\begin{array}{c}1 \\
(0.22 \mathrm{sec} .\end{array}$ & 2 & 12 \\
\hline \multicolumn{4}{|c|}{ Primary pulmonary hypertension .. } & 0 & 0 & $\begin{array}{c}1 \\
\text { (Long P-R) }\end{array}$ & $\begin{array}{c}1 \\
(0.22 \mathrm{sec} .)\end{array}$ & 0 & 2 \\
\hline \multicolumn{3}{|c|}{ Pulmonary artery thrombosis } & .. & 0 & $\mathbf{0}$ & 1 & 0 & 0 & 1 \\
\hline Total acquired & .. & . & .. & 7 & 6 & 5 & 4 & 30 & 23 \\
\hline Tetralogy of Fal & .. & .. & .. & $\mathbf{0}$ & $\mathbf{0}$ & 11 & $5 \ddagger$ & 0 & 13 \\
\hline Pure pulmonary & enosis & .. & .. & 0 & 0 & $3^{*}$ & $\begin{array}{c}2 \\
\text { (with } \mathrm{RA}+\text { ) }\end{array}$ & 0 & 10 \\
\hline Congenital pulm & ary hyp & pertensic & & 0 & 0 & 2 & 0 & 0 & 5 \\
\hline Total congenital & .. & .. & ․ & 0 & 0 & 16 & 7 & 0 & 28 \\
\hline
\end{tabular}

RA+ $=$ Right atrial $P$ wave.

LA+ $=$ Left atrial P wave.

$\mathrm{RA}+\mathrm{LA}+=$ Combined atrial $\mathrm{P}$ wave (see text).
* Two with prolonged $\mathbf{P}-\mathbf{R}$.

$+0 \cdot 22$ sec.; $0 \cdot 24$ sec. (with $\mathrm{R}$ and $\mathrm{LA}+$ ).

$\ddagger 3$ cases with P-R $0 \cdot 24$ sec.;

2 cases with P-R 0.22 sec. (RA+ in 4).

\section{Various Factors in Right Ventricular Hypertrophy}

The results of further studies to determine the causes for the greater degree of cardiographic R.V. hypertrophy in congenital than in acquired disease will now be presented. The following measurements have been compared.

(a) Right ventricular systolic pressure, (i) with voltage of $\mathrm{R}$ in $\mathrm{V} 4 \mathrm{R}$ in cases with a dominant $R$ wave, (ii) with $R / S$ ratio in V4R in all cases, and (iii) with $R / S$ ratio in V5 in all cases. 
(b) Total pulmonary vascular resistance with $\mathrm{R} / \mathrm{S}$ ratio in V4R and in V5.

(c) In the autopsied cases, the ratio of right ventricular to left ventricular thickness with $\mathrm{R} / \mathrm{S}$ ratio in V4R and V5.

(d) An attempt at grading of severity of R.V. hypertrophy has been made, and this grading has been compared with the R.V. systolic pressure, total pulmonary resistance, duration of symptoms, and ratio of right and left ventricular thickness.

\section{(a) Right Ventricular Systolic Pressure}

There is a positive correlation between the height of the dominant $R$ in V4R in those cases showing evidence of R.V. hypertrophy in this lead, and the R.V. systolic pressure $(C=0.65)$. Fig. 1 shows the correlation between $R / S$ ratios in $V 4 R$ and the pressure $(C=0 \cdot 76)$. $S / R$ ratios

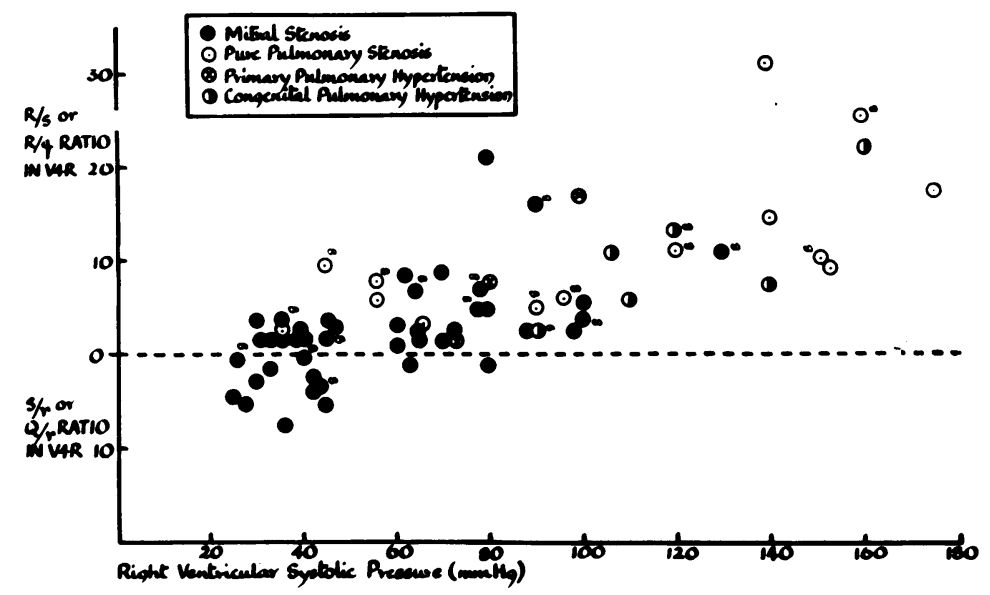

FIG. 1.-Right ventricular systolic pressure plotted against $R / S$ ratio in V4R in mitral stenosis, primary pulmonary hypertension, pulmonary artery thrombosis, congenital pulmonary hypertension, and pure pulmonary stenosis. Correlation coefficient. (C) $=0.76 . \infty=$ Monophasic R wave. (In patients with an $R / S$ ratio of less than unity, the $S / R$ ratio has been plotted for ease of presentation. The correlation coefficient has been derived from $\mathbf{R} / \mathbf{S}$ ratios, including those less than unity.)

have been plotted instead of $\mathrm{R} / \mathrm{S}$ ratios when the latter have been less than 1 , for clarity of presentation. Although there is a significant trend for the $R / S$ ratio to increase with the $R$.V. systolic pressure there is considerable scatter, especially in the mitral cases. Thus a R.V. systolic pressure of $60 \mathrm{~mm}$. $\mathrm{Hg}$ was associated with $\mathrm{R} / \mathrm{S}$ ratios ranging from 9 to less than 1 . However, when it exceeded this level, the $R / S$ ratio was unity or more in all but two cases. The results indicate that the $R / S$ ratio in V4R is little guide to the degree of R.V. hypertrophy in the slight to moderate ranges of R.V. hypertrophy. By contrast, the congenital cases generally had higher R.V. systolic pressures, and the $R / S$ ratio was never less than 1 . But in two cases with R.V. systolic pressures between 40 and $60 \mathrm{~mm}$. $\mathrm{Hg}$, the $\mathrm{R} / \mathrm{S}$ ratio exceeded 5 in both.

When the R.V. systolic pressure was plotted against the R/S ratio in V5 a trend was seen in the direction of smaller ratios with higher pressures, and there was a poor negative correlation $(\mathrm{C}=-0.45)$ (Fig. 2). Few mitral cases showed a ratio of less than 1, and this was never seen when the right ventricular systolic pressure was below $60 \mathrm{~mm}$. $\mathrm{Hg}$.

There was a tendency for smaller $\mathrm{R} / \mathrm{S}$ ratios (larger $\mathrm{S}$ waves) in the cases of pulmonary stenosis than for the mitral cases for comparable R.V. systolic pressures, suggesting, as in V4R, a more severe degree of cardiographic R.V. hypertrophy in the former group than in the latter. This difference must be due to factors other than R.V. hypertension. Extreme R.V. hypertension was 


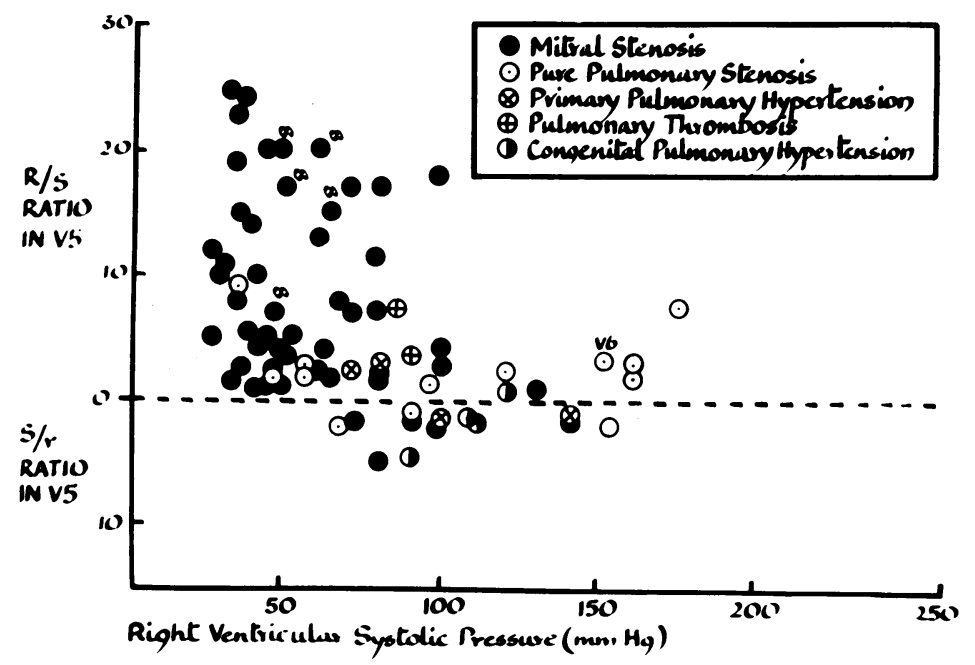

FIG. 2. Right ventricular systolic pressure plotted against $\mathbf{R} / \mathbf{S}$ ratio in lead V5 in the same groups of cases as in Fig. 1. Correlation coefficient (C) $=-0.45 . \infty=$ Monophasic $R$ wave. (The $S / R$ ratio has been taken when the $R / S$ ratio was less than unity, as in Fig. 1, and the correlation coefficient calculated in the same way.)

associated with striking R.V. dominance, irrespective of the diagnosis (Fig. 3A), but when hypertension was moderate, congenital disease tended to produce a greater degree of dominance than did mitral disease (Fig. 3B).

\section{(b) Total Pulmonary Vascular Resistance}

The total pulmonary vascular resistance was calculated by dividing the mean pulmonary artery pressure by the cardiac output and expressing the result as simple units of resistance, the maximum normal being regarded as 4 units. Fig. 4 and 5 show the pulmonary resistance plotted against the $R / S$ ratio in V4R and V5 in the mitral cases, in those with primary pulmonary hypertension, and in 5 of the 7 cases of congenital pulmonary hypertension. There is a poor positive correlation between resistance and $R / S$ ratio in $V 4 R(C=0 \cdot 46)$, and a poor negative correlation between resistance and the $\mathrm{R} / \mathrm{S}$ ratio in V5 $(\mathrm{C}=-0 \cdot 55)$. With one exception, a resistance of over 10 units was always accompanied by an $\mathrm{R} / \mathrm{S}$ ratio of 1 or more in $\mathrm{V} 4 \mathrm{R}$, but by contrast, an $\mathrm{R} / \mathrm{S}$ ratio of greater than 1 was frequently found with a pulmonary resistance of less than 10 units, and in one case with a pulmonary resistance of only 4 units. This shows clearly that factors other than pulmonary vascular resistance and R.V. systolic pressure are concerned in the production of a dominant $\mathbf{R}$ wave in V4R.

In V5, with one exception, a dominant $S$ wave ( $R / S$ ratio less than 1$)$ was present only when the pulmonary resistance exceeded 16 units, and a dominant $R$ wave ( $R / S$ ratio greater than 1$)$ was found in only two cases in which the pulmonary resistance exceeded 16 units, and in one of these the $R$ wave was only slightly larger than the $S$. These results suggest that the $R / S$ ratio in V5 may be a better guide to pulmonary resistance than the $R / S$ ratio in V4R, and that the pattern in V5 is determined more by pulmonary resistance than by other factors.

\section{(c) Ratio of Right to Left Ventricular Thickness}

Measurements of ventricular thickness from which the ratio could be derived were available in 28 cases. In the total group, there was a strongly positive correlation between this ratio and the $R / S$ ratio in V4R $(C=0.93)$, and a less impressive negative correlation with the $R / S$ ratio in V5. 


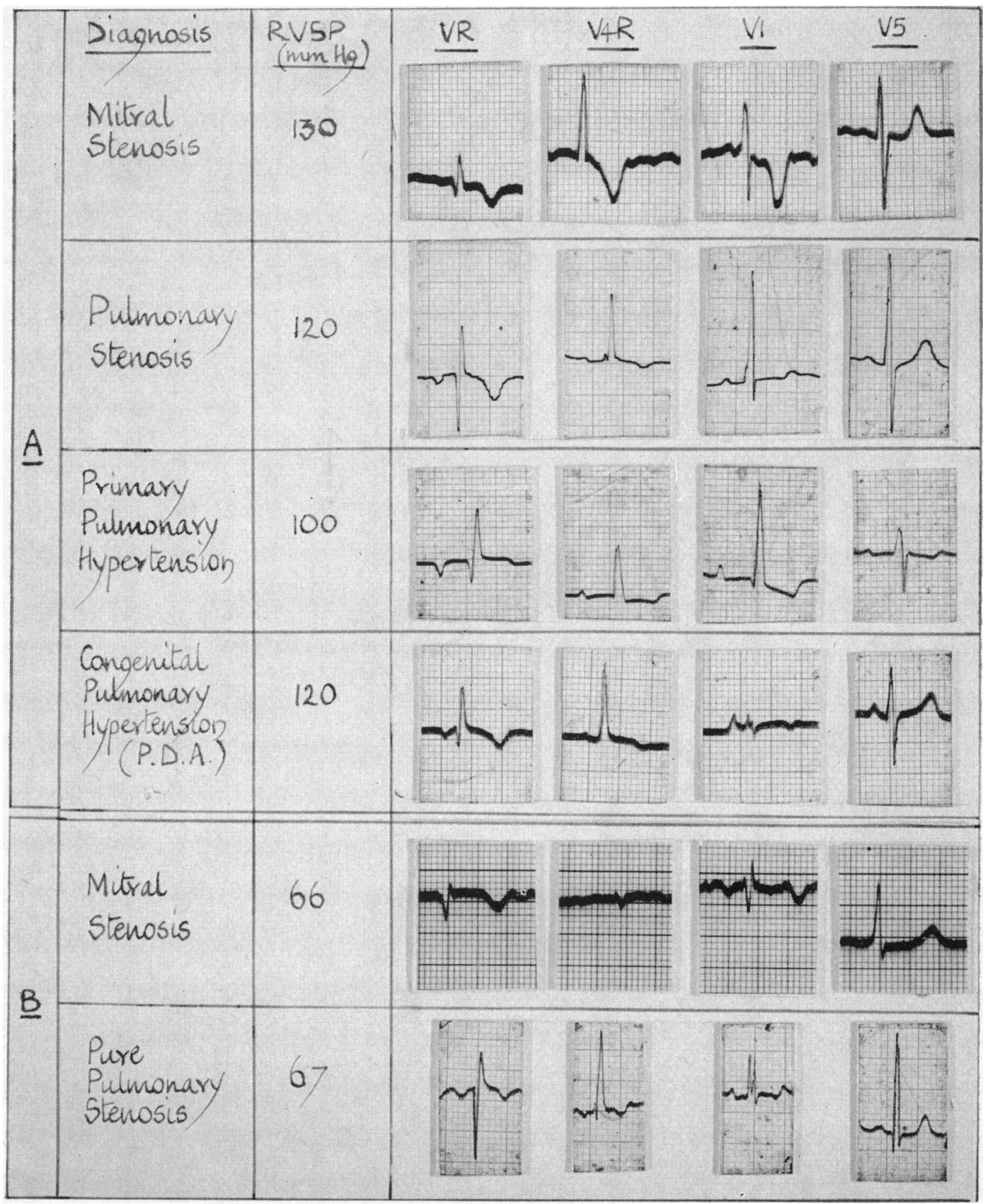

FIG. 3.-(A) Leads VR, V4R, V1 and V5 in 4 patients with similar systolic pressures in the right ventricle to show similar degrees of cardiographic R.V. hypertrophy despite differing diagnosis. (B) The same leads in mitral stenosis and in pure pulmonary stenosis show that greater cardiographic R.V. hypertrophy can occur in the latter despite R.V. systolic pressure equal to the former. Contrast with Fig. 8A: see text. RVSP $=$ R.V. systolic pressure. 


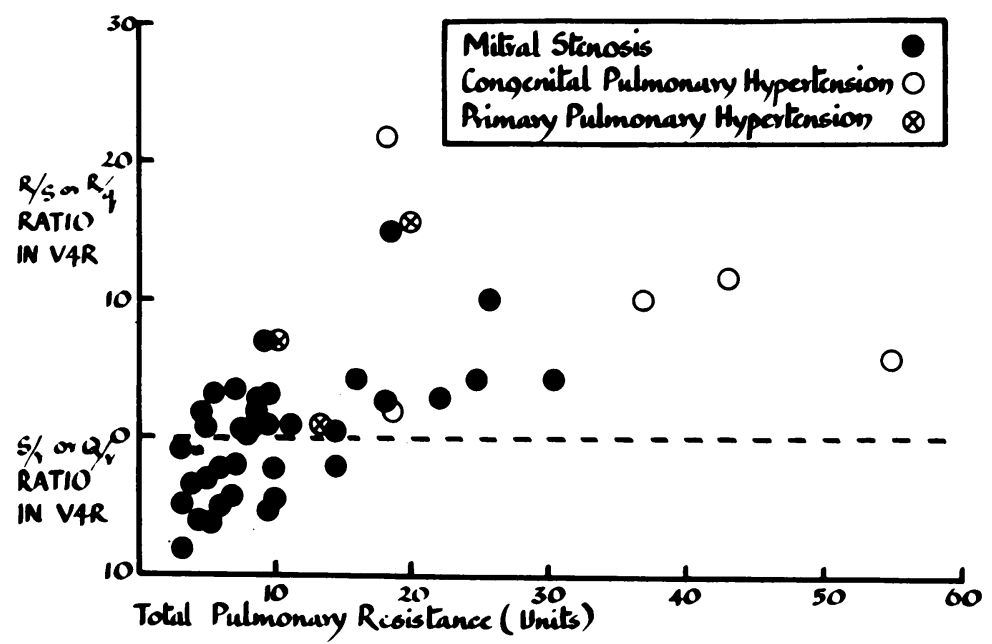

FIG. 4. - Total pulmonary vascular resistance plotted against $\mathbf{R} / \mathbf{S}$ ratio in lead V4R in mitral stenosis, with or without pulmonary hypertension, and in primary pulmonary hypertension. Correlation coefficient $(C)=0.46$. ( $\mathrm{S} / \mathrm{R}$ ratio plotted as before.)

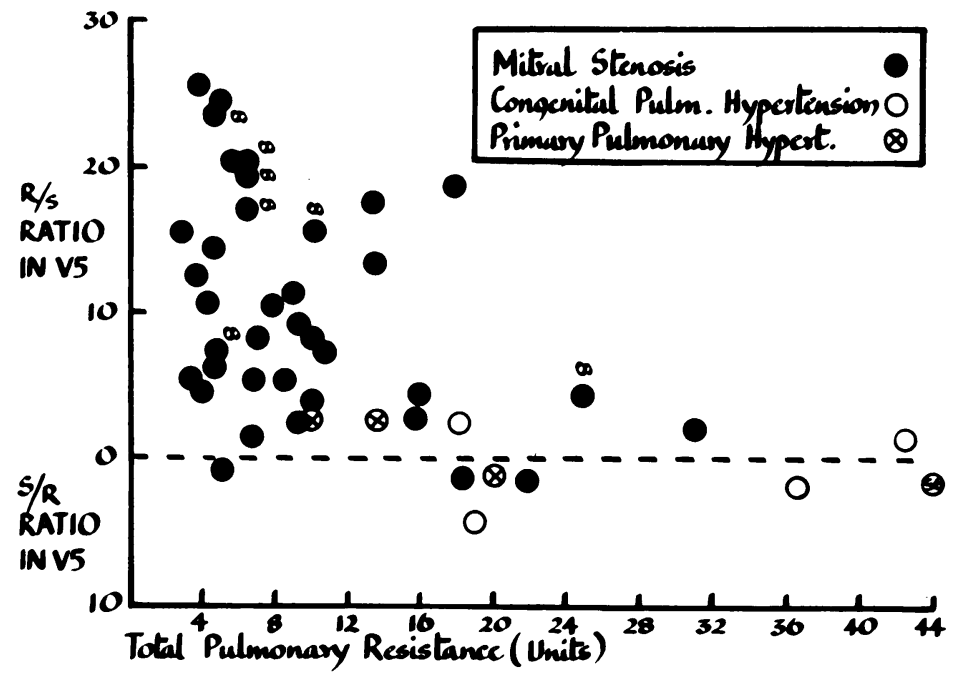

FIG. 5.-Total pulmonary vascular resistance plotted against $\mathbf{R} / \mathbf{S}$ ratio in lead V5 in the same cases as Fig. 4. Correlation coefficient $(C)=$ -0.55 . $\infty=$ Monophasic $R$ wave. (S/R ratio plotted as before.)

$(C=-0.48)$ (Fig. 6 and 7). The correlation between the signs of R.V. hypertrophy in V4R and V5 and the R.V./L.V. ratio was least good in the seven mitral cases, probably because four of them had some left ventricular hypertrophy in addition to right, which was absent in all but one of the other cases.

The autopsy results therefore suggest that there is some relationship between these cardiographic signs of R.V. enlargement and the anatomical degree of R.V. hypertrophy, but that the latter is not the sole determinant of these signs. 


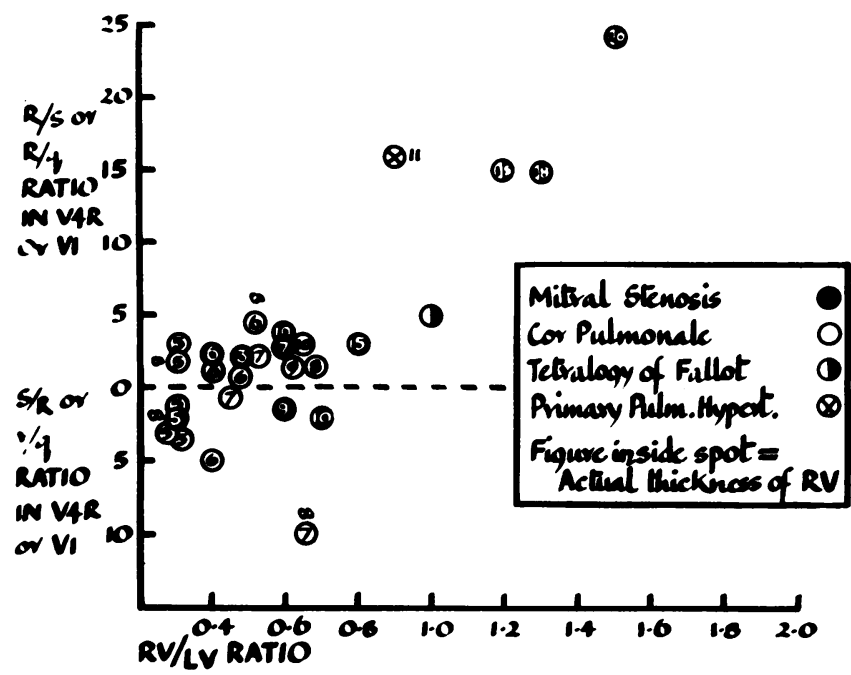

Fig. 6.-Ratio of thickness of right ventricle to left ventricle (R.V./L.V. ratio) plotted against $R / S$ ratio in lead V4R or V1 in mitral stenosis, cor pulmonale, tetralogy of Fallot, and primary pulmonary hypertension. Figure inside circles represents actual thickness of right ventricle. Correlation coeffcient $(C)=0.93$. $\infty=$ Monophasic $R$ wave. (S/R ratio plotted as before.)

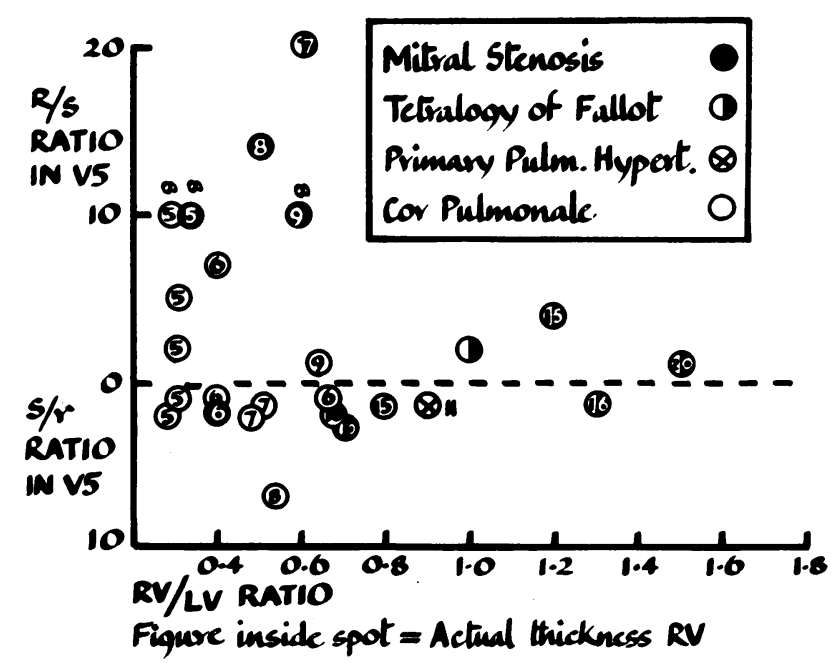

FIG. 7.-Ratio of thickness of right ventricle to left ventricle (R.V./L.V. ratio) plotted against $\mathbf{R} / \mathrm{S}$ ratio in lead V5 in the same cases as in Fig. 6. Figures inside circles represent actual thickness of right ventricle. Correlation coefficient (C) $=-0.48$. $\infty=$ Monophasic $R$ wave. (S/R ratio plotted as before.) 


\section{(d) Cardiographic Grading of Degree of R.V. Hypertrophy}

It was apparent that no single cardiographic sign provided an adequate assessment of the amount of R.V. hypertrophy, or more than a rough correlation with the possible causes, such as R.V. systolic pressure, pulmonary vascular resistance, and R.V. thickness. A system of grading was therefore introduced and based upon the ventricular complexes in V4R, V1, and V5, as follows.

Grade 0. Normal ventricular balance. $\mathrm{rS}$ in V4R and V1, qR or Rs in V5; dominant negative deflection in VR.

Grade 1. Dominant $\mathrm{R}$ wave in $\mathrm{V} 4 \mathrm{R}$ only; or dominant $\mathrm{S}$ in $\mathrm{V} 5$ only.

Grade 2. Dominant $\mathrm{R}$ wave in V4R and V1; or dominant $\mathrm{R}$ wave in V4R, with dominant $\mathrm{S}$ in V5; or $\mathbf{R}$ in VR.

Grade 3. Dominant $\mathrm{R}$ in $\mathrm{V} 4 \mathrm{R}$ and $\mathrm{V} 1$, with dominant $\mathrm{R}$ in $\mathrm{VR}$ and $\mathrm{S}$ in V5.

Grade 4. Dominant or monophasic $\mathrm{R}$ in V4R of $10 \mathrm{~mm}$. or more; with or without QR pattern; dominant RV1; dominant SV5; with or without dominant $\mathrm{R}$ in VR, and T inversion in right præcordial leads.

A dominant $\mathrm{S}$ wave in V5, without dominant $\mathrm{R}$ in V4R or V1, has been shown often, but not invariably, to result from biventricular hypertrophy (Goodwin, 1958), and was consequently only very rarely seen in this series. The rS pattern in V5 often represents a considerable degree of R.V. hypertrophy, which is usually accompanied by a dominant $\mathbf{R}$ in right præcordial leads unless this is diminished by associated left ventricular hypertrophy. It is therefore difficult to determine the grade of R.V. hypertrophy on the basis of the $\mathrm{rS}$ pattern in V5 alone. We have, however, arbitrarily assigned the lone rS V5 pattern to grade 1, realizing that it may sometimes represent a more severe degree of R.V. hypertrophy, partly masked by left ventricular hypertrophy.

$T$ wave changes were comparatively infrequent and inconstant, but, when deep $T$ wave inversion accompanied a dominant $\mathrm{R}$ in right præcordial leads and a dominant $\mathrm{S}$ in V5, the cardiogram has been regarded as grade 4 . P wave changes indicating right atrial hypertrophy have not been introduced into the grading system.

It is realized that such a grading system cannot be exact in the presence of so many variables, and that some cases will not always fit neatly into one of the four grades. However, the system is well adapted to the majority of cases. Table IX shows the grade of R.V. hypertrophy in the total series. As with the individual signs of R.V. hypertrophy in single leads, the congenital cases show a more severe degree of R.V. hypertrophy than the mitral cases. The cases of cor pulmonale occupy an intermediate position, half showing signs of appreciable R.V. hypertrophy in contrast with the

TABLE IX

Grade of Right Ventricular HyPertrophy in all Groups

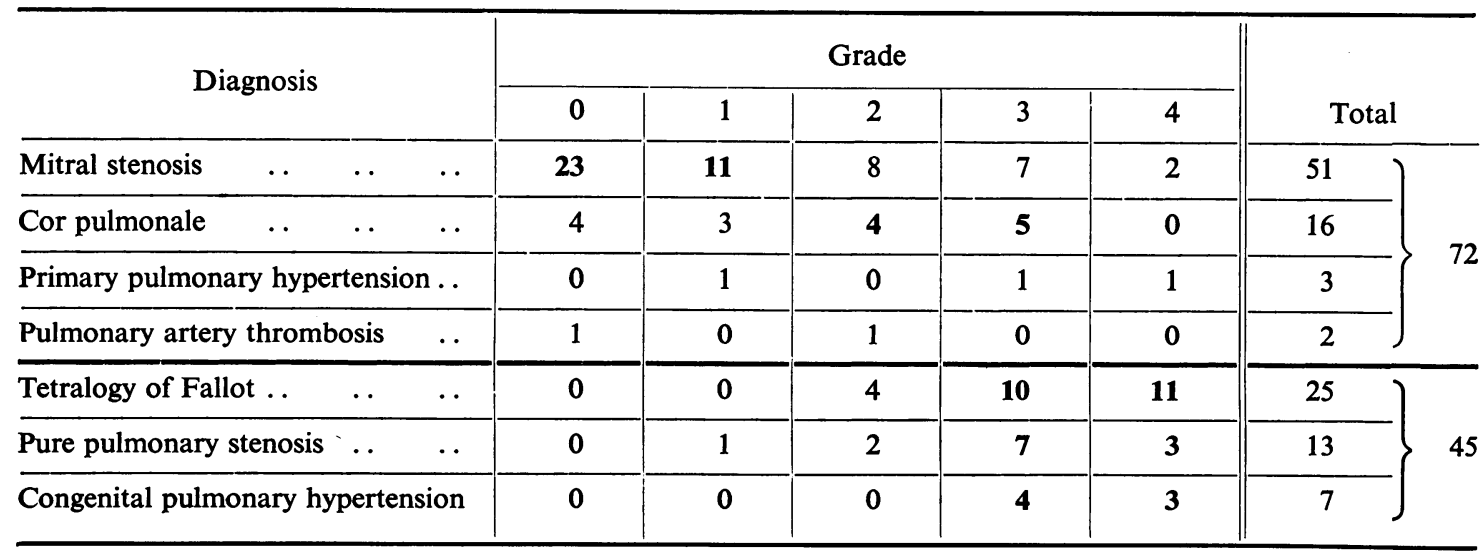


mitral cases in which the majority showed little evidence of R.V. hypertrophy. Two of the three cases of primary pulmonary hypertension showed severe degrees of R.V. hypertrophy similar to the congenital cases.

The grade of R.V. hypertrophy has been compared with the right ventricular systolic pressure, total pulmonary vascular resistance, R.V./L.V. ratio, and duration of symptoms.

As would be expected, the grade of R.V. hypertrophy increased steadily with the R.V. systolic pressure, although there was considerable scatter (Fig. 8A). The average R.V. systolic pressure for grade 0 R.V. hypertrophy was 43; for grade 1, 55; for grade 2, 75; for grade 3, 79; and for grade 4, $125 \mathrm{~mm}$. Hg. Grade $4 \mathrm{R}$.V. hypertrophy was never seen with a R.V. pressure of less than $78 \mathrm{~mm}$. $\mathrm{Hg}$, but grade 3 was seen with a pressure of only just over $40 \mathrm{~mm}$. $\mathrm{Hg}$. There was no sharp division between the grades and pressures, but a regular trend was noted. No difference was seen between congenital and acquired groups, except a tendency for higher grades of R.V. hypertrophy to be associated with lower pressures in pure pulmonary stenosis than in mitral disease.

The same trends were noted between the grade of R.V. hypertrophy and the pulmonary resistance (Fig. 8B and 9). The ranges of pulmonary resistance for grades 0 and 1 were identical, and the
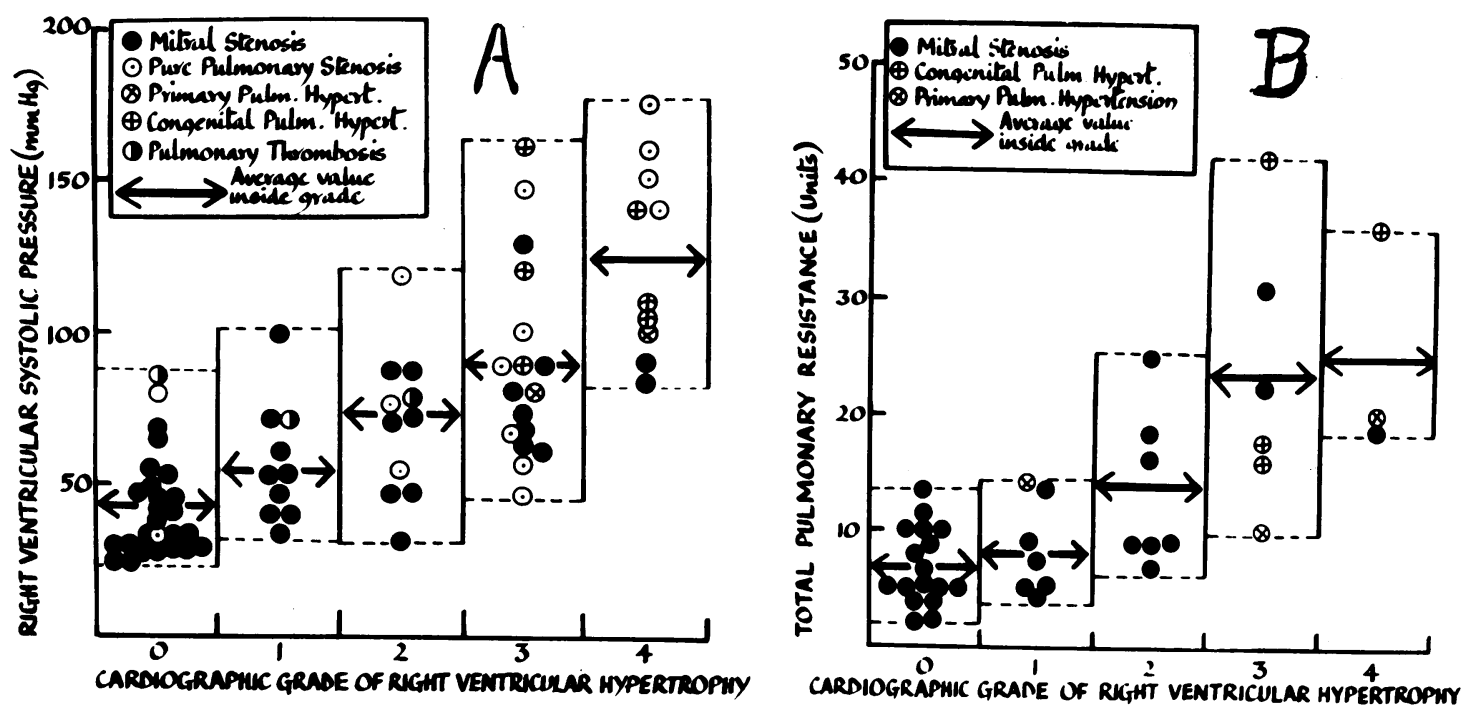

FIG. 8.-Cardiographic grade of R.V. hypertrophy in mitral stenosis, primary pulmonary hypertension, pulmonary artery thrombosis, pure pulmonary stenosis, and congenital pulmonary hypertension, plotted (A) against right ventricular systolic pressure, and (B) against total pulmonary vascular resistance. The average pressure and resistance respectively for each grade of $R$.V. hypertrophy is shown as an arrow within each grade.

average resistance was only very slightly higher for grade 1 ( 8 as compared with 6.6 units). There was also little difference between grades 3 and 4 . There was a distinct difference, however, between grades 1 and 2 on the one hand, and grades 3 and 4 on the other, the average pulmonary resistance in grade 4 being 25 units, and in grade 1, 8 units. Grade 2 was intermediate, with an average of $13 \cdot 8$ units.

The same order of scatter was seen when the R.V./L.V. thickness ratio was compared with the grade of R.V. hypertrophy, although there was also a trend towards higher grades being associated with greater R.V. thickness, and this was more obvious if the thickness of the right ventricle only was considered (Fig. 6, 7, and 10). In particular, the cases of the tetralogy of Fallot showed grade 3 or $4 \mathrm{R} . \mathrm{V}$. hypertrophy and R.V./L.V. ratios greater than 1 . The cases of cor pulmonale also showed a good correlation between R.V./L.V. ratio and grade of R.V. hypertrophy, with the 
exception of two cases with grade 3 R.V. hypertrophy, a normal R.V./L.V. ratio of 0.3 , and minimal anatomical R.V. hypertrophy (R.V. thickness, $5 \mathrm{~mm}$.).

Table X shows the 39 autopsy cases, with the right and left ventricular thickness in the 28 in which these were obtained, and the cardiographic grade in each case. Table XI gives the maximum,

TABLE X

Ventricular Thickness and Cardiographic Grade in 39 Autopsy Cases

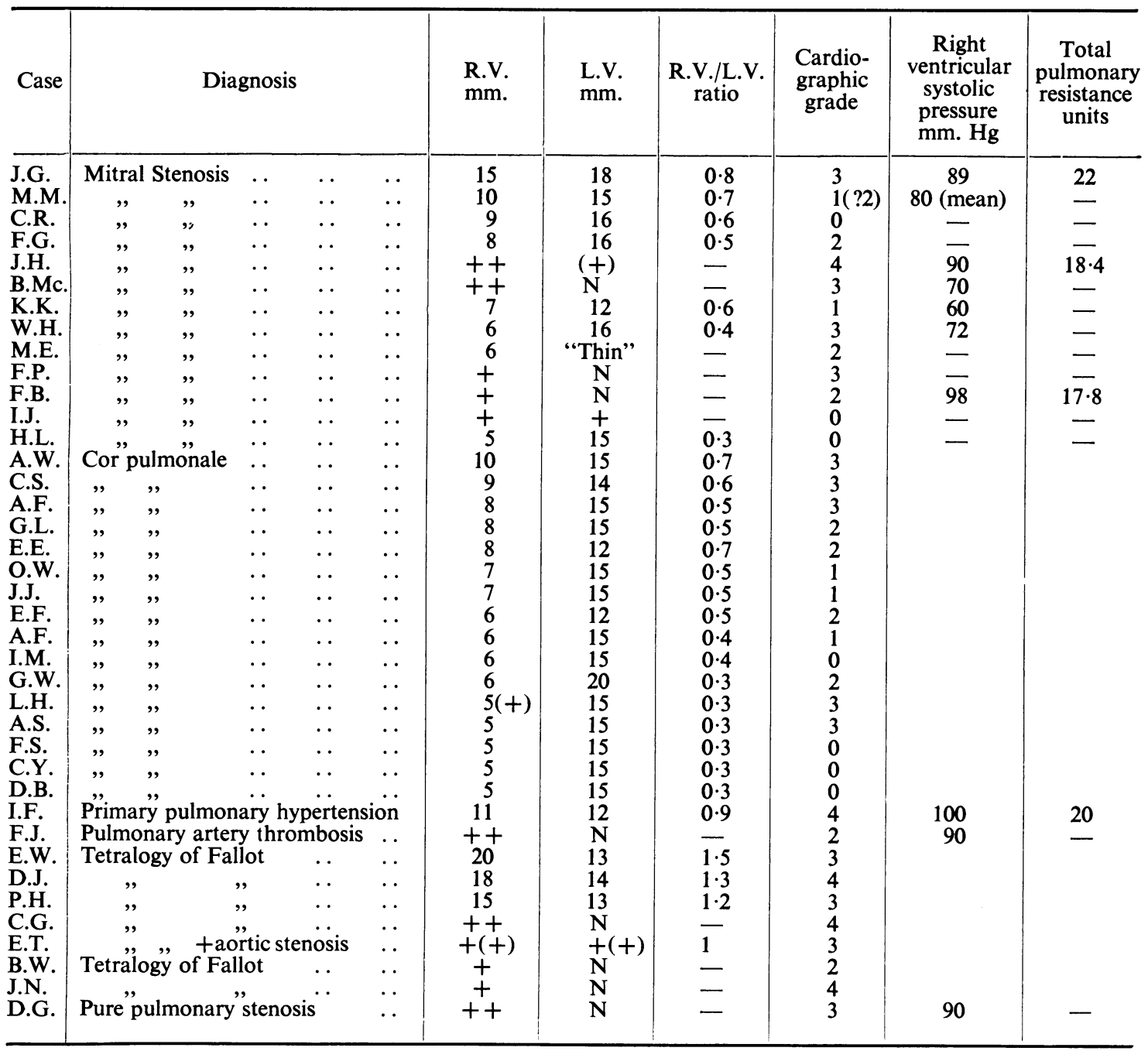

$\mathbf{N}=$ Normal.

Case M.M. (Mitral Stenosis) had an rS pattern in V5 without a dominant $\mathrm{R}$ in V4R.

minimum and average R.V./L.V. ratios for each grade of R.V. hypertrophy. The figures in each group are too small for statistical analysis, but there is a trend for cardiographic R.V. hypertrophy to increase with increasing R.V./L.V. ratios.

The comparison between duration of symptoms and grade of R.V. hypertrophy showed little except that the acquired cases with grades 3 and 4 R.V. hypertrophy had a history of severe symptoms of less than five years, sometimes under one year, whereas in the congenital group the history was 


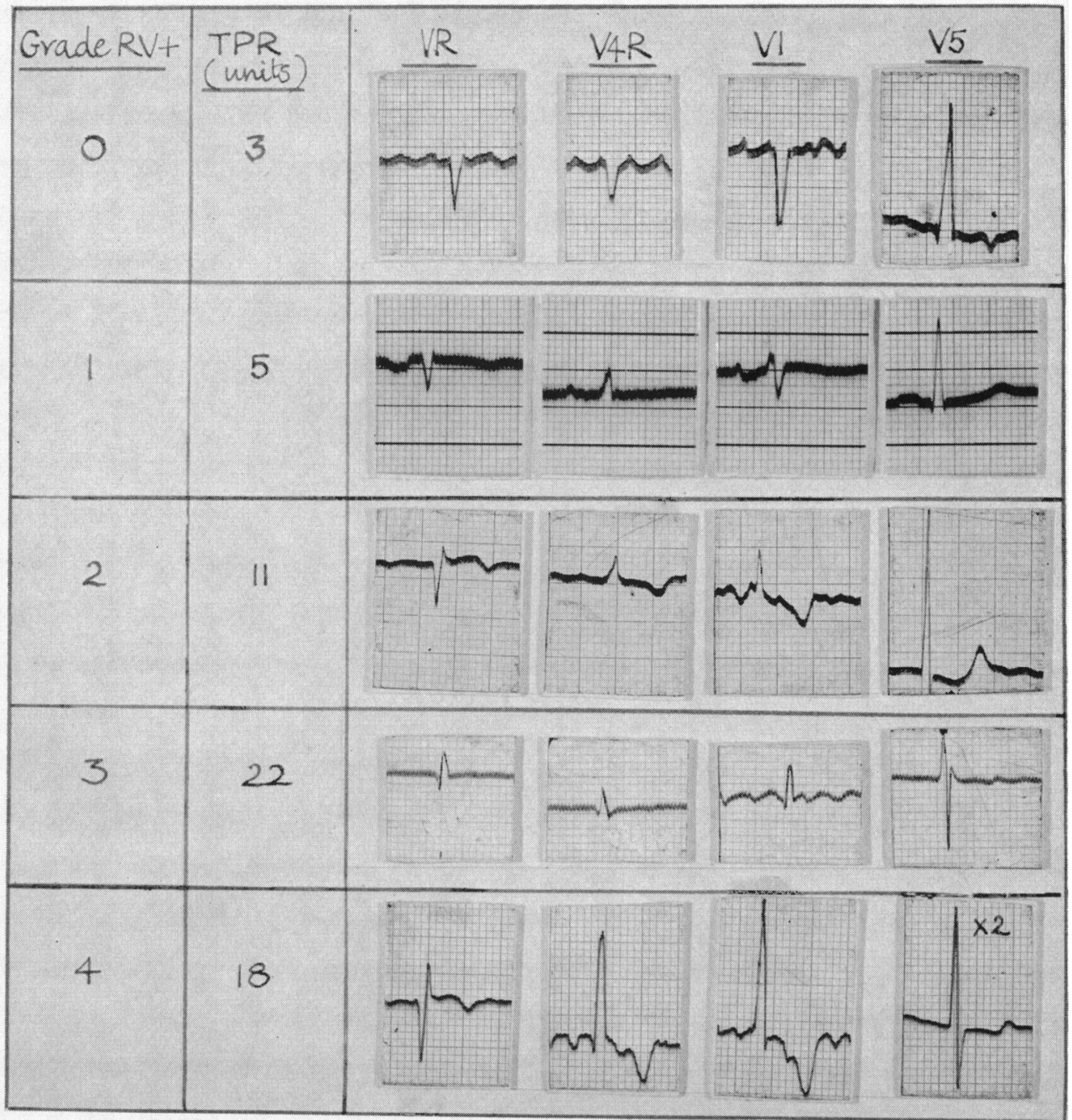

Fig. 9.-Leads VR, V4R, V1, and V5 in five patients with mitral stenosis, to show that the cardiographic grade of R.V. hypertrophy increases with the total pulmonary resistance (TPR).

TABLE XI

Ratio of R.V. to L.V. thickness and Grade of Right Ventricular Hypertrophy in 28 Cases

\begin{tabular}{c|c|c|c|c}
\hline $\begin{array}{c}\text { Grade of right } \\
\text { ventricular } \\
\text { Hypertrophy }\end{array}$ & \multicolumn{3}{|c|}{ R.V./L.V. Ratio } & Number of cases \\
\cline { 2 - 5 } & Maximum & Minimum & Average & \\
\hline 0 & 0.6 & 0.3 & 0.37 & 6 \\
\hline 1 & 0.7 & 0.4 & 0.52 & 5 \\
\hline 2 & 0.7 & 0.3 & 0.50 & 5 \\
\hline 3 & 1.5 & 0.3 & 0.73 & 10 \\
\hline 4 & 1.3 & 0.9 & 1.1 & 2 \\
\hline
\end{tabular}




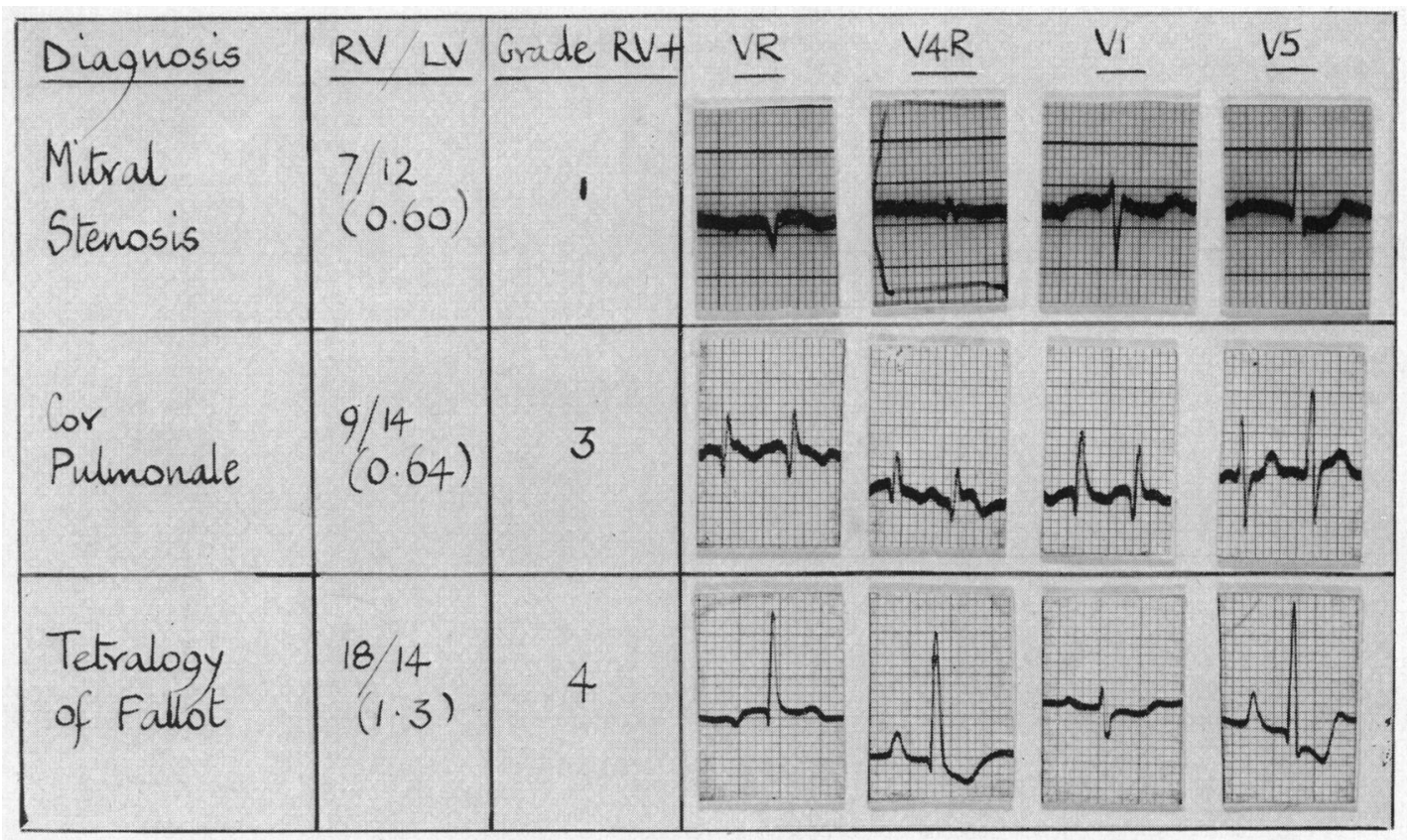

FIG. 10.-Leads VR, V4R, V1, and V5, R.V./L.V. ratio, and cardiographic grade of R.V. hypertrophy in mitral stenosis, cor pulmonale, and tetralogy of Fallot to show increasing grade of R.V. hypertrophy with increasing R.V./L.V. ratio and thickness of the right ventricle. Note the presence of only minimal evidence of $R$.V. hypertrophy on the cardiogram of the patient with mitral stenosis despite increased R.V. thickness without left ventricular hypertrophy. (R.V./L.V. ratio = ratio of thickness of R.V. (in mm.) to thickness of L.V. (in mm.))

longer. Duration of R.V. hypertrophy was assessed on the basis of duration of severe symptoms in the acquired group, and the age of the patient in the congenital cases, on the assumption that the factors producing R.V. hypertrophy had been present since birth.

\section{Discussion}

This study indicates the tendency for greater degrees of cardiographic R.V. hypertrophy in congenital than in acquired cases, when this is assessed both by individual leads and by grading of the complete cardiogram. It also confirms the importance of leads V4R, V5, and VR, in the diagnosis of R.V. hypertrophy. The difference between the acquired and congenital cases is due mainly to greater R.V. systolic pressure, pulmonary vascular resistance, and R.V. thickness in the congenital groups. The considerable scatter when each of these measurements is compared with the cardiographic patterns suggests that multiple rather than single factors operate to produce the cardiographic signs of R.V. hypertrophy.

Of special interest is the variability between the different groups of cases within the main groups. The cases of cor pulmonale showed greater degrees of R.V. hypertrophy than did the mitral cases, although they did not generally show a greater R.V. thickness at autopsy. However, no hæmodynamic measurements were available in the cor pulmonale series, and it may be that they had in general higher pulmonary resistances than the mitral cases. Also, the three cases of idiopathic pulmonary hypertension had higher pulmonary resistances than the mitral cases, and two of these showed cardiographic degrees of R.V. hypertrophy resembling the congenital cases.

In spite of the general tendency for the degree of R.V. hypertrophy to be dependent upon the factors already mentioned rather than upon the ætiology, there was a slight tendency for the con- 
genital cases to show a greater degree of R.V. hypertrophy than the acquired for similar levels of R.V. systolic pressure, and pulmonary resistance. Possible additional factors that may be considered to produce cardiographic signs of R.V. hypertrophy are the duration of hypertrophy; right ventricular dilatation, and rotation of the cardiac vector; enlargement of the left ventricle; and myocardial disease.

\section{Duration of Right Ventricular Hypertrophy}

It is difficult to arrive at an accurate estimate in acquired cases, but we have taken the duration of severe or disabling, as opposed to slight or trivial, dyspnœa as indicative of the shortest probable duration of R.V. hypertrophy. In many cases, however, it will have been present before the onset of such symptoms. In the congenital cases it can be assumed that hypertrophy was present from birth, and therefore these cases have had it much longer than many of the acquired group. It would be expected that the longer the duration of R.V. hypertrophy, the greater its cardiographic signs, and this is generally true in the congenital group, although many patients in the younger age ranges have such extreme cardiographic R.V. hypertrophy, that it cannot show any increase with time.

In the acquired group, no general trend can be discerned, but it is of interest that the cases with extreme (grades 3 and 4) R.V. hypertrophy tended to have a short history of dyspnœa. However, a short history was also found in cases with lesser hæmodynamic evidence of R.V. hypertrophy. Thus the mitral cases with grade 3 or 4 R.V. hypertrophy had a history of severe dyspnœa of less than 3 to 5 years, and some less than 1 year, while only one case with this degree of R.V. hypertrophy had a longer history.

There is, furthermore, a fundamental difference in ventricular balance between the congenital and acquired groups. In the congenital group, the pathological R.V. hypertrophy is added to the normal R.V. dominance present at birth so that at no time is the left ventricle dominant. This must favour the development of striking cardiographic signs, those of pathological R.V. hypertrophy being added to those of physiological R.V. hypertrophy. By contrast, in acquired R.V. hypertrophy, the left ventricle is normally dominant for many years, and when R.V. hypertrophy develops, it must become considerable before cardiographic signs of it appear. As would be expected, when the right ventricle is thicker than the left, striking cardiographic R.V. hypertrophy is present, but slighter signs also occur when the enlarged right ventricle is still appreciably smaller than the left ventricle. This period of normal left ventricular dominance in the acquired cases is likely to be an important factor in determining the lesser degrees of right ventricular hypertrophy usually seen in these cases. Also the ratio of R.V./L.V. thickness is usually much greater in the congenital than in the acquired cases (Table X).

The tendency for patients with acquired R.V. hypertrophy and considerable or gross cardiographic signs to have a short history of dyspnœa suggests that with a previously unprepared ventricle, a rapid increase in pulmonary resistance may determine a more severe degree of cardiographic R.V. dominance, than when the right ventricle has been prepared by a slower development of hypertension. But the evidence available is insufficient to permit a definite answer on this point.

\section{Cardiac Rotation and Ventricular Dilation}

Neither of these factors can readily be measured, but may well be concerned in the production of signs of R.V. dominance. Acute dilatation and rotation is thought to account for the cardiographic appearances in pulmonary embolism, when the principal changes often consist of a deep $\mathrm{S}$ wave in V5 (clockwise rotation), right præcordial $\mathrm{T}$ wave inversion, and characteristic changes in the standard limb leads. Personal experience has shown that a dominant $R$ wave can also develop in V4R in these circumstances, and disappear after a short interval (Goodwin, unpublished observation). It is therefore reasonable to suppose that lesser signs of R.V. hypertrophy may be 
due largely to cardiac dilatation, and rotation of the vector, which produces mainly positive forces in right præcordial leads. We have previously pointed out that a dominant $R$ wave in V4R or V1 need not be due to increased right ventricular thickness (Camerini et al., 1956). We have also shown that a dominant $\mathrm{R}$ wave in V4R has rapidly disappeared after relief of heart failure. This disappearance was too rapid to be due to regression of hypertrophy and must have been due to relief of dilatation.

We believe that the signs produced by dilatation usually consist of a small dominant $R$ wave in V4R, and clockwise rotation. Rasmussen and Boe (1951) in a study of the natural history of the cardiogram in mitral stenosis considered dilatation of the right ventricle was of major importance in determining the cardiographic changes. Dilatation and rotation may therefore account for some of the discrepancies between R.V. systolic pressure, pulmonary resistance, R.V. thickness, and cardiographic degrees of R.V. hypertrophy. Dilatation and rotation, especially if transient, may cause difficulty in the grading of R.V. hypertrophy, since a patient may have a severe degree of R.V. hypertrophy, during or after an episode of heart failure, which may become considerably less after treatment. It is very probable in these cases that the pulmonary resistance rises considerably during the episode, and then falls after recovery. The increase in cardiographic right ventricular hypertrophy with increase in right ventricular systolic pressure in cor pulmonale during heart failure has been mentioned already (Mounsey et al., 1952).

The greater incidence of extreme clockwise rotation (rS in V5) in the cor pulmonale group than in the mitral cases is of interest. A decrease in the $R$ wave and increase in the $S$ wave in V6 was noted by Thomas (1951) in cases with severe right ventricular hypertrophy due to pneumoconiosis. It might be suggested that a great degree of dilatation occurred in these cases, but the rS V5 pattern was also a feature in cases of the tetralogy of Fallot in which ventricular dilatation is unusual.

\section{Associated Left Ventricular Enlargement}

The rarity of equal $\mathrm{R}$ and $\mathrm{S}$ waves, or of a dominant negative deflection in V5 in mitral stenosis is of interest, and may be related to the influence of the left ventricle. We have previously shown that the presence of left ventricular enlargement may obscure the cardiographic signs of right ventricular hypertrophy completely or partially (Pagnoni and Goodwin, 1952; Goodwin, 1958), and that an $\mathrm{rS}$ pattern in V5 without a dominant $\mathrm{R}$ wave in V4R may be due to the suppression of the right præcordial $R$ wave by the left ventricular hypertrophy.

In the present series every effort was made to exclude cases with any clinical evidence of left ventricular hypertrophy. Nevertheless, this may have been present to a modest degree in some cases as a result of slight aortic disease or mitral regurgitation, which were present in a minority. Associated left ventricular hypertrophy could certainly account for diminished evidence of right ventricular hypertrophy, and in many cases of acquired heart disease must be a factor in suppressing cardiographic signs of R.V. hypertrophy. Only one of the cor pulmonale patients, however, had any pathological evidence of left ventricular hypertrophy, whereas 4 of 7 of the autopsy cases of mitral stenosis had an increase in thickness of the left ventricular wall. This left ventricular enlargement, even if slight and clinically indetectable because of the much greater R.V. hypertrophy, might be the cause of suppression of the deep S wave in V5 in mitral stenosis. Conversely, the presence of an $\mathrm{rS}$ in V5 associated with dominant $\mathrm{R}$ in V4R in mitral disease argues not only a considerable degree of R.V. hypertrophy and elevation of pulmonary vascular resistance, but also absence of any left ventricular hypertrophy.

In mitral disease, extreme right ventricular dominance is uncommon. The absence of such dominance in mitral cases with other evidence of considerable right ventricular stress, possibly suggests some involvement of the left ventricle.

\section{Myocardial Disease}

The possibility that disease of the myocardium as distinct from hypertrophy might influence the cardiogram must be briefly considered. Personal experience has shown that changes in the chest 
leads may occur in mitral stenosis as a result of cardiac infarction following coronary embolism, and these changes may closely mimic R.V. hypertrophy. One of us (J. F. G.) has previously described the resemblance between certain forms of anterior infarction and R.V. hypertrophy (Goodwin, 1958). It is therefore likely that myocardial damage, whether ischæmic or otherwise, will modify the pattern of R.V. hypertrophy. Furthermore, such damage may cause enlargement of the left ventricle (Hollman, 1958). Although coronary embolism is considered rare in mitral stenosis, it might be the explanation for otherwise inexplicable left ventricular hypertrophy in mitral stenosis. Four such cases were reported by McDonald et al. (1957) but the cause was not suggested.

\section{CONCLUSIONS AND SUMmaRY}

The cardiographic signs of right ventricular hypertrophy are unquestionably more pronounced in congenital than in acquired disease. The difference is due mainly to greater right ventricular systolic pressures, pulmonary vascular resistances, and right ventricular thickness, and to the absence of left ventricular hypertrophy, in the congenital group. The progression from physiological to pathological right ventricular dominance without an intervening period of left ventricular dominance in the congenital group is probably an important contributory cause.

Cor pulmonale and primary pulmonary hypertension appear to resemble the congenital rather than the mitral cases in their degree of right ventricular hypertrophy. The reasons for this are not clear, but the duration of the acquired hypertrophy may have some influence, and the results suggest that in acquired cases the rapid onset of severe pulmonary and right ventricular hypertension may produce a more severe degree of right ventricular dominance than when the development is more gradual.

Acute dilatation of the right ventricle and rotation of the vector have been shown temporarily to produce or increase signs of right ventricular dominance independent of hypertrophy, and it is possible that recurrent acute episodes of pulmonary hypertension which are perhaps more likely to occur in cor pulmonale than in mitral stenosis may have some bearing on the differences. The infrequent occurrence of severe (grades 3 and 4) R.V. hypertrophy in mitral disease is due to at least two causes. First, to the comparative rarity of extreme degrees of right ventricular hypertension and pulmonary resistance (such as are frequently seen in congenital cases), and second to the association of left ventricular enlargement which suppresses the signs of R.V. hypertrophy. The left ventricular enlargement is usually the result of associated mitral regurgitation, systemic hypertension, or aortic valve disease, but in an undetermined proportion of cases may be the result of myocardial damage due to ischæmia or other cause. Such myocardial damage may modify the cardiogram without producing left ventricular hypertrophy.

The cardiographic patterns are of some value in predicting the severity of the disease. In mitral stenosis, while a slight degree of right ventricular hypertrophy may be associated with considerable increase in pulmonary resistance, the reverse is not true, and a grade 4 cardiogram guarantees a right ventricular systolic pressure in the region of $80 \mathrm{~mm}$. $\mathrm{Hg}$, or a total pulmonary resistance of around 20 units. A dominant $\mathrm{S}$ wave in V5 in association with a dominant $\mathrm{R}$ in V4R suggests considerable right ventricular hypertrophy without appreciable left ventricular hypertrophy. Slight increases in pulmonary resistance cannot be predicted from grade 1 right ventricular hypertrophy since both grade 0 and grade 1 occur over an identical range of pulmonary resistance.

In the cases of congenital pulmonary hypertension, the grade of right ventricular hypertrophy (3 or 4) correlates well with the right ventricular systolic pressure and pulmonary resistance, both of which were greatly raised. This is also true in the pure pulmonary stenosis cases, but with one or two exceptions. In general, however, a grade 3 cardiogram suggests a right ventricular systolic pressure in the region of $75 \mathrm{~mm}$. $\mathrm{Hg}$ or more, and a grade 4 cardiogram indicates pressures above $100 \mathrm{~mm}$. Hg.

The cardiogram is less helpful in predicting the severity in Fallot's tetralogy as the right ventricular systolic pressure is at systemic level in all cases because of the ventricular septal defect and aortic over-ride. However, the majority of cases show a grade of right ventricular hypertrophy 
comparable with that in pure pulmonary stenosis, although there is a greater tendency for right præcordial T wave inversion in the latter. Cabrera and Monroy (1952) have suggested that dominant $R$ waves and $T$ wave inversion in right præcordial leads indicate "systolic overload" of the right ventricle. Since the right ventricle can develop a higher pressure than the left in pure pulmonary stenosis, and therefore can be forced to do more "pressure work" than in the tetralogy, this explanation would harmonize with the greater $T$ wave inversion in lone stenosis in this series. The presence of deep $\mathrm{T}$ wave inversion in V3 or V5 would thus favour a diagnosis of lone pulmonary stenosis rather than of the tetralogy. Anatomical right ventricular hypertrophy is usually gross in the cases of the tetralogy, indicating that this may be more important in determining the grade of right ventricular dominance than the right ventricular systolic pressure.

Finally the practice of grading the cardiographic severity of right ventricular hypertrophy may assist in the long-term assessment of the prognosis of patients who come to cardiac surgery.

We are greatly indebted to Mrs. Angela Birbeck and the Department of Medical Photography for the illustrations, and to Mr. Please and Mrs. Birbeck for statistical advice and assistance.

\section{REFERENCES}

Cabrera, C. E., and Monroy, J. F. (1952). Amer. Heart J., 43, 669.

Camerini, F., Goodwin, J. F., and Zoob, M. (1956). Brit. Heart J., 18, 13.

Campbell, M. (1952). Brit. Heart J., 14, 204.

Cosby, R. S., Levinson, D. C., Zinn, W. J., Dimitroff, S. P., and Griffith, G. C. (1952). Amer. Heart J., $44,581$.

Cosby, R. S., Levinson, D. C., Dimitroff, S. P., Oblath, R. W., Herman, L. M., and Griffith, G. C. (1953). Amer. Heart J., 46, 670 .

Davies, L. G., Goodwin, J. F., Steiner, R. E., and Van Leuven, B. D. (1953). Brit. Heart J., 15, 393

Fowler, N. O., Jr., Westcott, R. N., Scott, R. C. (1952). Circulation, 5, 441.

Goldberger, E. (1947). Unipolar Lead Electrocardiography. H. Kimpton, London.

Goodwin, J. F. (1952). Brit. Heart J., 14, 173.

(1958). Brit. Heart J., 20, 191.

, Cleland, W. P., Hunter, J. D., Davies, L. G., and Steiner, R. E. (1955). Brit. med. J., $2,573$.

Hollman, A. (1958). Personal communication.

McDonald, L., Dealy, J. B., Rabinowitz, M., and Dexter, L. (1957). Medicine (Baltimore), $36,237$.

Mounsey, J. P. D., Ritzmann, L., and Selverstone, N. J. (1952). Brit. Heart J., 14, 442.

Myers, G. B. (1950). Circulation, 1, 860.

$\longrightarrow$, Klein, H. A., and Stofer, B. E. (1948). Amer. Heart J., 35, 1.

Pagnoni, A., and Goodwin, J. F. (1952). Brit. Heart J., 14, 451.

Rasmussen, H., and Böe, J. (1951). Cardiologia (Basle), 18, 33.

Rosenman, R. H. (1950). Amer. Heart J., 40, 522.

Scott, R. C., Kaplan, S., Fowler, N. O., Jr., and Stiles, W. J. (1955). Circulation, 11, 761.

Sokolow, M., and Lyon, T. P. (1949). Amer. Heart J., 38, 273.

Thomas; A. J. (1951). Brit. Heart J., 13, 1.

Trounce, J. R. (1952). Brit. Heart J., 14, 185.

Walker, I. C., Helm, R. A., and Scott, R. C. (1955). Circulation, 11, 215.

, Scott, R. C., and Helm, R. A. (1955). Circulation, 11, 223.

Whitaker, W. (1954). Quart. J. Med., 23, 105.

Wilson, F. N., Johnston, F. D., Rosenbaum, F. F., Erlanger, H., Kossmann, C. E., Hecht, H., Cotrim N, de Oliveira, M., Scarsi, R., and Barker, P. S. (1944). Amer. Heart J., 27, 19.

Woods, A. (1952). Brit. Heart J., 14, 193. 